\title{
The evolution of autistic-like and schizotypal traits: a sexual selection hypothesis
}

\author{
Marco Del Giudice*, Romina Angeleri, Adelina Brizio and Marco R. Elena \\ Center for Cognitive Science, Department of Psychology, University of Turin, Turin, Italy
}

Edited by:

lan Penton-Voak, University of Bristol,

UK

\section{Reviewed by:}

Daniel Nettle, University of Newcastle, UK

Lars Penke, University of Edinburgh, UK

*Correspondence:

Marco Del Giudice, Department of Psychology, University of Turin, Via Po

14, 10123 Torino, Italy.

e-mail:marco.delgiudice@unito.it
In this paper we present a new hypothesis on the evolution of autistic-like and schizotypal personality traits. We argue that autistic-like and schizotypal traits contribute in opposite ways to individual differences in reproductive and mating strategies, and have been maintained - at least in part - by sexual selection through mate choice. Whereas positive schizotypy can be seen as a psychological phenotype oriented to high-mating effort and good genes displays in both sexes, autistic-like traits in their non-pathological form contribute to a male-typical strategy geared toward high parental investment, low-mating effort, and long-term resource allocation. At the evolutionary-genetic level, this sexual selection hypothesis is consistent with Crespi and Badcock's "imprinted brain" theory of autism and psychosis; the effect of offspring mating behavior on resource flow within the family connects sexual selection with genomic imprinting in the context of human biparental care. We conclude by presenting the results of an empirical study testing one of the predictions derived from our hypothesis. In a sample of 199 college students, autistic-like traits predicted lower interest in short-term mating, higher partner-specific investment, and stronger commitment to long-term romantic relations, whereas positive schizotypy showed the opposite pattern of effects.

Keywords: autistic-like traits, schizotypal traits, genomic imprinting, mating strategies, personality, sexual selection

\section{INTRODUCTION}

In this paper we present a new hypothesis on the evolution of autistic-like and schizotypal personality traits. We argue that autistic-like and schizotypal traits contribute in opposite ways to individual differences in reproductive and mating strategies, and have been maintained - at least in part - by sexual selection through mate choice. Whereas positive schizotypy can be seen as a psychological phenotype oriented to high-mating effort and good genes displays in both sexes (Nettle, 2001; Shaner et al., 2004), autistic-like traits in their non-pathological form contribute to a male-typical strategy geared toward high parental investment, low-mating effort, and long-term resource allocation. At the evolutionary-genetic level, our sexual selection hypothesis is consistent with Crespi and Badcock's "imprinted brain" theory of autism and psychosis (Crespi and Badcock, 2008a,b). The diametrical effects of autistic-like and schizotypal traits on mating behavior indirectly modulate the flow of resources between parents and their adult offspring, thus linking the imprinted brain theory to recent evolutionary models of genomic imprinting under biparental care (Úbeda, 2008).

The hypothesis we present here is admittedly speculative, and so are many of the models that constitute its theoretical background. We do not claim to have proven our case beyond reasonable doubt, nor that we can presently rule out alternative evolutionary scenarios. Our intent is to advance a bold theoretical argument that, if correct, would have many crucial implications for our understanding of autistic-like personality traits and their genetic basis. The usefulness of our hypothesis lies in its heuristic potential, as it can stimulate researchers to reinterpret existing data and ask new empirical questions that would not be asked otherwise. For this reason - and for the sake of brevity - we do not attempt to review the strengths and weaknesses of each of the theories we refer to (e.g., the imprinted brain theory, the creativity models of schizotypy, or the extreme male brain theory of autism) nor to discuss every possible objection or alternative. Rather, our goal is to lay out the background assumptions of our argument as clearly as possible, while providing key references to published criticism for the interested reader.

After a brief introduction to the measurement of autistic-like and schizotypal traits (see Autistic-Like and Schizotypal Traits) we review the imprinted brain theory, the sexual selection models of schizotypy, and the extreme male brain theory of autism (see Evolutionary Theories). We complete the theoretical background with an overview of individual differences in human reproductive and mating strategies (see Variability in Human Reproductive and Mating Strategies). In Section "A Sexual Selection Hypothesis" we present our sexual selection hypothesis, and in Section "Sexual Selection and the Imprinted Brain Theory" we connect it with the imprinted brain theory through the generalized kinship theory of genomic imprinting (Úbeda, 2008). In Section "An Empirical Test" we present the results of an empirical study testing one of the predictions derived from our hypothesis in a sample of college students.

\section{AUTISTIC-LIKE AND SCHIZOTYPAL TRAITS}

Autistic-like and schizotypal traits can be described as continuously distributed dimensions of normal personality, with pathological extremes represented by autism-spectrum disorders [including Kanner autism, Asperger syndrome (AS), and Turner syndrome] and psychotic-spectrum disorders (including schizophrenia, bipolar disorder and major depression). Most people display moderate degrees of one or both kinds of traits, and even possessing them at 
relatively high levels does not imply the presence of a disorder. The view of autistic-like and schizotypal traits as heritable dimensions of normal individual variation receives considerable support in the current literature; dozens of papers have been published dealing with the measurement of these traits, their genetic architecture and their behavioral correlates.

Schizotypy (see Claridge, 1997) is a classical psychological concept, and many different scales measuring it have been developed over the last 50 years. Schizotypal traits can be broadly grouped in two categories: positive schizotypy (unusual cognitive and perceptual experiences, tendency to magical ideation, reference and paranoid thoughts) and negative schizotypy (social isolation and anxiety, reduced emotional expression). Positive-schizotypal traits tend to be somewhat higher in females, while negative schizotypy is generally higher in males (see Sex Differences and Age-Related Variation). Positive schizotypy is associated with creativity (e.g., Weinstein and Graves, 2002; Nettle, 2006; Nettle and Clegg, 2006; Batey and Furnham, 2008) and is considerably higher in artists than in scientists (Rawlings and Locarnini, 2008).

More recently, Baron-Cohen et al. (2001) developed a measure of autistic-like traits in the non-clinical range, the Autism-spectrum Quotient (AQ). The AQ evaluates cognitive and personality features such as reduced communicative ability/social skills, reduced attention switching and repetitive behavior, interest in patterns and details, and low imagination. These facets are correlated but also exhibit independent variation, and probably have distinct genetic and neurobiological bases (reviewed in Happé and Ronald, 2008). Autistic-like personality traits are higher in males and in people with technicalscientific interests and careers. Among undergraduates, AQ scores are highest in the physical sciences and mathematics, intermediate in the biological sciences, and lowest in the humanities (Baron-Cohen et al., 2001; Austin, 2005; Wheelwright et al., 2006).

It is crucial to keep in mind that - despite the strong negative connotation of the word "autism" - autistic-like traits in the normative range do not imply psychopathology, nor do they necessarily represent dysfunctional aspects of one's personality; on the contrary, they can promote success in some types of activities. For example, an individual high in autistic-like traits may show reduced social sensitivity, a strong desire for order and control on his/her environment, and single-mindedness in the pursuit of his/ her interests. This can lead to independent and self-directed behavior, unconventionality, and the acquisition of highly useful skills. Moreover, autistic-like traits are associated with increased attention to detail, better visuo-spatial skills, and enhanced low-level sensory processing in the visual and auditory domains (Baron-Cohen et al., 2009; Grinter et al., 2009). Indeed, the autistic-like facets of repetitive behaviors, restricted interests, and detail-oriented cognitive style correlate with the development of outstanding talents in middle childhood (Happé and Vital, 2009). If the charming, eccentric artist is the folk prototype of socially successful schizotypy, the technically minded engineer or computer scientist may well be the modern prototype of a successful autistic-like personality.

\section{CORRELATIONS BETWEEN AUTISTIC-LIKE AND SCHIZOTYPAL TRAITS}

To date, only a handful of studies have investigated the correlation between autistic-like and schizotypal traits in the general population. In a study by Hurst et al. (2007a), autistic-like traits were more strongly related to negative ( 0.53$)$ than to positive-schizotypal traits (0.25); however, partial correlation analysis showed that these associations were largely due to covariation between the "social skills" and "communication" scales of the AQ and negative schizotypy. The other scales only showed small to negligible unique associations with one another. Another study was carried out by Rawlings and Locarnini (2008) on a mixed sample including musicians, visual artists and scientists. Total AQ score showed a correlation of 0.05 with the main positive schizotypy index and 0.52 with the main negative schizotypy index. Finally, Rawlings (2008) found a moderate correlation of autistic-like traits with positive schizotypy (0.32) and a stronger one with negative schizotypal traits (0.62). Unfortunately, the authors of these studies did not analyze the individual and partial correlations of AQ scales with schizotypal traits.

The empirical overlap between autistic-like and negative schizotypal traits requires careful interpretation. As discussed by Crespi and Badcock (2008b) with respect to clinical syndromes, autistic-spectrum disorders and negative psychotic symptoms share a number of phenotypically similar aspects including affective flatness, social isolation and poor communication skills. However, these behavioral similarities, rather than indicating common processes at work, could be only superficial and possibly misleading. The situation is even worse with questionnaires measuring personality traits in the non-clinical range: item wording is often vague and does not address the psychological reasons for a given behavior, thus creating substantial overlap between scales because of sheer item similarity. Consider for example these items from the AQ "social skill" scale: "I find social situations easy," "I enjoy meeting new people," and "I prefer to do things with others rather than on my own" (all reverse-scored), and compare them with the following ones from the negative scales of the Schizotypal Personality Questionnaire (SPQ; Raine, 1991): "I have little interest in getting to know other people," "I prefer to keep myself to myself," "I tend to keep in the background on social occasions." Autistic-like individuals may find social situations difficult because they do not easily tune into other people's mental states, because they are less knowledgeable of social conventions and unspoken rules, or because it is harder for them to hold a conversation on topics they find personally uninteresting. In contrast, schizotypal individuals may experience other people's distancing reaction to their lack of emotional expressivity, or feel at the center of attention and become anxious and preoccupied about what others are thinking about them. Both processes would result in social uneasiness (as assessed by questionnaire items), but the underlying reasons could hardly be more different. In this sense, the overlap between negative schizotypy and the social skills/communication scales of the AQ could reflect the non-specific effects of the underlying traits on mood and social relations.

In summary, positive schizotypy and autistic-like traits seem to be nearly orthogonal in the non-clinical population. Negative schizotypy, in contrast, shows substantial overlap with some subscales measuring autistic-like traits - but it is far from clear whether this reflects common functional mechanisms or just superficial phenotypic similarity.

\section{SEX DIFFERENCES AND AGE-RELATED VARIATION}

Autistic and psychotic syndromes are characterized by a sex-biased pattern of incidence. Autism is dramatically more frequent in males (upto 10:1 in Asperger and high-functioning syndromes; 
Baron-Cohen, 1999, 2003); the distribution of schizophrenia is slightly male-biased overall, but positive symptoms are relatively more common in females (Räsänen et al., 2000; Aleman et al., 2003). For this reason, autistic-like and schizotypal traits can also be expected to show a sexually dimorphic distribution in nonclinical populations.

Autistic-like traits assessed with the AQ are consistently higher in males than in females. In student samples, effect sizes (Cohen's $d$ ) for total AQ scores range from -0.03 to 0.35 (positive values indicate higher scores in males; Baron-Cohen et al., 2001; Wheelwright et al., 2006; Hurst et al., 2007a,b), with smaller sex differences in samples of psychology students. In community and mixed samples, effect sizes range from about 0.30 to 0.40 (Baron-Cohen et al., 2001; Austin, 2005; Hoekstra et al., 2007).

Positive schizotypy is usually higher in females, with typical $d$ values around -0.10 to -0.30 depending on the scale (e.g., Raine, 1992; Ross et al., 2002; Fossati et al., 2003; Williams and Barry, 2003; Mata et al., 2005; Badcock and Dragović, 2006). Negative schizotypy, on the other hand, shows consistently higher levels in males, with effect sizes typically around $0.20-0.60$; unfortunately, it is hard to tell how much of the sex difference in negative schizotypy scales may actually be due to their high phenotypic overlap with autistic-like traits.

It is interesting to note that schizotypal traits peak in adolescence/young adulthood and show a marked decline with age (Venables and Bailes, 1994; Claridge et al., 1996; Fossati et al., 2003), a trend consistent with evolutionary models of schizotypy based on mating effort (see Schizotypy and Mating). No comparable data exist as yet on age-related changes in autistic-like traits. However, between 3 and $25 \%$ of people diagnosed with autism-spectrum disorders recover from the disorder as they grow older; recovery is more likely for those with higher IQ and early communication/ language abilities (reviewed in Helt et al., 2008). In particular, communicative deficits tend to improve more than repetitive behavior (Seltzer et al., 2004).

\section{EVOLUTIONARY THEORIES THE IMPRINTED BRAIN THEORY}

Crespi and Badcock (2008a) advanced the hypothesis that autisticspectrum syndromes and psychotic-spectrum syndromes represent pathological extremes of individual differences in the cognitive dimensions that define the human "social brain." The autistic extreme is characterized by high mechanistic and low mentalistic cognition: a cognitive profile more suited to interaction with the physical world (e.g., good visuo-spatial abilities and cause-effect inference) than with other human beings (e.g., communication deficits, reduced empathy and social understanding). In contrast, psychosis is characterized by hyper-mentalistic and hypo-mechanistic cognition: hyper-mentalizing (e.g., paranoid ideation, increased sensitivity to non-verbal cues, over-responsiveness to gaze) is associated with poor visuo-spatial abilities, failure in logical reasoning, and so on (see also Abu-Akel and Bailey, 2000). This "people/ things" dichotomy (similar but not identical to Baron-Cohen's empathizing/systemizing distinction; see The Extreme Male Brain Theory of Autism) is by no means limited to clinical conditions such as autism and schizophrenia; indeed, Crespi and Badcock (2008a) described a spectrum of normal variation in personality and cognition, with most people showing more or less balanced combinations of mechanistic and mentalistic abilities. Thus, the imprinted brain theory can be applied to non-clinical variation in autistic-like and schizotypal traits. However, whereas Crespi and Badcock hypothesized the existence of a single mechanisticmentalistic continuum, the empirical data reviewed in Section "Autistic-Like and Schizotypal Traits" are more consistent with a two-dimensional model of autistic-like and positive schizotypal traits. Indeed, the diametrical features of autistic versus psychotic disorders (representing highly unbalanced cognitive profiles) do not imply a negative correlation between the underlying personality traits in the normal population.

In this framework, some facets of autistic-like traits can be seen as reflecting higher levels of mechanistic cognition (e.g., interest in details, patterns, and mechanical/abstract systems), while others relate to reduced mentalistic cognition (e.g., social skill, mind-reading, and empathy). Turning to positive schizotypy, some of its facets relate to hyper-mentalistic cognition (e.g., paranoid and reference thoughts, magical ideation), while others concern unusual perceptual and cognitive experiences and cannot be readily linked to the imprinted brain theory. It is important to note that hyper-mentalistic cognition needs not be always accurate; indeed, schizotypal individuals may often ascribe other people emotions and mental states in a vivid but idiosyncratic way, as when - for example - they experience the feeling that someone can "read their minds" or when they suspect that people are talking behind their backs. Some smallsample studies have found correlations between schizotypy and poorer performance in theory of mind tasks (e.g., Langdon and Coltheart, 1999; Pickup, 2006; Shean et al., 2007), although a recent large study did not replicate these findings (Fernyhough et al., 2008; see also Jahshan and Sergi, 2007). In particular, negative schizotypy is associated with lower self-reported empathy and poorer sense of humor; this may partly depend on its overlap with autistic-like traits (see Correlations Between Autistic-Like and Schizotypal Traits). On the contrary, positive schizotypy is associated with higher self-reported empathy and increased appreciation of jokes (Henry et al., 2008; Rawlings, 2008). In keeping with their eccentric profile, however, high-schizotypy individuals also display idiosyncratic and unusual interpretations of irony (Langdon and Coltheart, 2004).

\section{Genomic imprinting and the social brain}

A central feature of Crespi and Badcock's theory is their hypothesis that the diametrical phenotypes of autistic and psychotic disorders are underlain (at least in part) by a diametrical genetic process: the conflict between maternally and paternally expressed imprinted genes. Imprinted genes are genes that vary in their level of expression depending on their parent of origin; for example, in the case of maternally expressed genes, the paternally derived allele is partially or totally silenced by epigenetic mechanisms (DNA methylation and/or histone modifications), and only the maternally derived one is actually expressed in the individual. The kinship theory of genomic imprinting (Haig, 1997, 2000, 2004; see also Wilkins and Haig, 2003; Burt and Trivers, 2006) is an evolutionary-genetic extension of kin selection and parent-offspring conflict models that links the activity of imprinted genes to the modulation of 
parental investment (and, more generally, to the modulation of interest conflicts between the matriline and the patriline due to asymmetric relatedness).

The kinship theory predicts that, in species characterized by maternal investment and at least some degree of multiple paternity (i.e., asymmetric relatedness), paternally expressed genes will evolve so as to increase resource transfer from the mother to the offspring (e.g., by increasing fetal placentation and growth rate, or by up-regulating food intake and hunger in the infant); conversely, maternally expressed genes should affect development in the opposite direction, so as to reduce the mother's investment in a given offspring. The kinship theory of imprinting predicts a costly conflict between maternal and paternal alleles, and has been successfully applied to several instances of parent-specific genetic expression (Haig, 2004). It is important to note that the net effect of imprinted genes on a given trait is usually relatively small, as in a tug-of-war between equally strong teams. The full force of the underlying conflict is revealed only when balance is disrupted, for example when an entire section of the paternally inherited chromosome is deleted or duplicated.

Since many imprinted genes are expressed in the central nervous system (Davies et al., 2005; Isles et al., 2006), it is reasonable to expect them to modulate maternal investment at the behavioral level rather than just by physiological means. For example, imprinted genes may regulate parental investment by affecting investment-demanding behaviors in the child - including crying, attention-seeking, emotional dysregulation, dependency, and so on (Brown and Consedine, 2004; Isles et al., 2006). Indirect evidence suggests that imprinted genes are probably involved in the regulation of critical neurotransmitter systems such as dopamine, serotonin, and GABA. There are also cues that imprinted genes may exert an impact on the oxytocin and vasopressin systems, which are crucially involved in the neurobiology of parent-child attachment (Davies et al., 2008).

Crespi and Badcock (2008a,b) argued that autistic-spectrum syndromes involve a "paternally biased brain," i.e., a severe overexpression of paternally expressed genes (and/or under-expression of maternally expressed genes), whereas psychosis is characterized by a "maternally biased brain," corresponding to over-expression of maternally expressed genes (and/or under-expression of paternally expressed genes). In addition to genetic data (see Badcock and Crespi, 2006; Crespi and Badcock, 2008b), these authors gathered a remarkable array of evidence showing that, in line with the genomic conflict hypothesis, autistic syndromes are generally associated with overgrowth patterns (e.g., high birth weight and length, high placentation, larger brain size and thicker cortex, faster body growth in childhood) while psychosis tends to be associated with undergrowth (e.g., low birth weight and length, low placental weight, slow growth in childhood, smaller brain size and thinner cortex). On the behavioral side, they proposed that autistic-spectrum children impose high costs on the mother because of their lack of empathy and other attention-demanding aspects of their behavior, while the increased empathy associated with schizotypy would make children less demanding and easier to enculturate, thus reducing the required amount of maternal investment. In this model, imprinted genes contribute substantially (but not exclusively) to the etiology of autism and psychosis. The same imprinted genes would also contribute to individual variation in the general personality dimensions of autistic-like traits and schizotypy - the focus of the present paper. Heritable individual differences may involve variation in genetic sequences as well as variation in the epigenetic patterns of imprinting at the same genetic loci. For critical appraisals of the imprinted brain theory, see Davies and Isles (2008), Dickins et al. (2008), and Keller (2008).

\section{SCHIZOTYPY AND MATING}

Several evolutionary models have been put forth to explain the persistence of psychosis-proneness in the human gene pool (see Keller and Miller, 2006, for a broad overview). Some researchers proposed that psychosis is a side effect of pleiotropic genes involved in the human capacity for language and/or culture (e.g., Horrobin, 1998; Crow, 2000), while others have emphasized the maladaptive role of fitness-reducing mutations (Keller and Miller, 2006). Here we focus on models that give a functional account of schizotypy from the perspective of mating and sexual selection; while speculative in many respects, these models have pointed to plausible evolutionary benefits of schizotypal traits, and have received promising empirical support in a number of recent studies.

\section{Schizotypy and creativity}

Nettle (2001) argued that positive schizotypy confers a direct reproductive advantage, especially at moderate levels and when the individual does not develop severe mental disorders. Even in individuals who eventually develop a damaging clinical condition, the benefits accrued before the onset of the condition may sometimes make up for the fitness costs caused by pathology. The reproductive benefits of positive schizotypy would stem from its association with creativity, which enhances attractiveness and contributes to successful courtship. In accord with this hypothesis, Nettle and Clegg (2006) found a significant relationship between self-reported positive schizotypy and mating success (i.e., number of sexual partners). In contrast, negative schizotypy appeared to decrease one's mating potential. The relationship between positive schizotypy and mating success was mediated by the intensity of creative activity. Nettle (2006) showed that poets and visual artists score as high as schizophrenic patients in positive-schizotypal traits, but lower than controls in negative schizotypy; furthermore, Haselton and Miller (2006) found that women tend to prefer highly creative men as short-term mates in the fertile phase of their cycle.

Despite the appeal of the creativity hypothesis, the exact nature of the relationship between schizotypy and creative activity is still open to debate. In particular, Miller and Tal (2007) argued that general intelligence and openness to experience may predict creativity better than schizotypal traits. In their sample of college students, schizotypy correlated with both creativity and openness; in a multiple regression model predicting creativity, the partial contribution of openness was statistically significant, while that of positive schizotypy was not. This statistical model, however, rests on the implicit assumption that the effect of openness has to be partialed out from that of schizotypy; in fact, Miller and Tal's data are equally consistent with a path model where openness fully mediates the effect of schizotypy on creativity (i.e., schizotypy increases openness which, in turn, augments creativity). Alternatively, the 
two constructs may tap some of the same psychological processes, and schizotypy might even be seen as a facet of the broader trait of openness to experience. Clearly, more research will be needed to fully make sense of the extant empirical data.

The most recent statements of Nettle's model largely converge with Miller and colleagues' hypothesis that schizotypal traits enhance the fitness-sensitivity of a sexually selected fitness indicator (see below). In a more speculative fashion, Nettle (2008) elaborated on Crespi and Badcock's (2008a) model, and suggested that one of the reasons why the schizotypal kind of creativity is attractive to women may lie precisely in the lower maternal investment demanded by offspring of schizotypal parents. In other words, schizotypy would signal a maternally biased genotype that can be expected to favor the matriline, thus limiting offspring's extraction of maternal resources; being attracted to signs of schizotypal personality could then be advantageous for women, especially if their partners' parental investment is going to be limited (that is, in short-term mating contexts).

\section{Schizotypy and fitness indicators}

The role of schizotypy in human mating has been further explored by Shaner et al. (2004, 2008a), whose evolutionary model treats psychotic-spectrum disorders (and more specifically schizophrenia) as the dysfunctional extreme of one or more sexually selected fitness indicators. Fitness indicators are traits with no immediate survival value, evolved through sexual selection to function as courtship ornaments due to their ability to reveal their bearer's genetic quality (lack of mutation load) and general conditions (Miller, 2000a,b). "Fit" individuals are able to display the attractive form of the trait, while individuals of low genetic quality and/or in poor conditions end up displaying its unattractive variant. In the model proposed by Shaner et al. (2004, 2008a), schizophrenia (whose typical symptoms are delusions, disorganized speech, reduced emotional expressiveness, poor sense of humor and impaired perspective taking) represents an aberrant form of human verbal courtship behavior, or, as the authors put it, a "catastrophic failure of mating intelligence." Highly successful forms of verbal courtship require the opposite features: humor, skilled mind-reading, verbal creativity and emotional attunement, and so on. Several strands of evidence appear to support the hypothesis by Shaner and colleagues: for example, the typical age of onset of psychotic symptoms (adolescence and early adulthood) coincides with the peak of mating effort, and there are sex differences in age of onset that may reflect the different timing of maximal sexual competition in males and females. Moreover, dopamine agonists - known to stimulate courtship behavior in many species - also worsen the symptoms of schizophrenia, while dopamine antagonists have the opposite effect (see Kahn and Davis, 1995; Shaner et al., 2008a).

In this framework, schizotypy can be seen as a sensitivityenhancing trait, so that high levels of schizotypal traits increase the correlation between genetic/environmental quality and mating displays. In other words, schizotypy would act as an "amplifier" of individual fitness as reflected in fitness-indicator traits, increasing both the risk of developing psychosis (when genetic quality is low and/or development is hampered by poor environmental conditions) and the likelihood of outstanding mating success (when genetic quality and environmental conditions are good).

\section{THE EXTREME MALE BRAIN THEORY OF AUTISM}

Baron-Cohen and colleagues (Baron-Cohen and Hammer, 1997; Baron-Cohen, 1999, 2002, 2003) have developed an influential theory of autism, based on the idea that autistic-spectrum syndromes are extreme, pathological manifestations of the typical male cognitive structure. Research on cognitive sex differences (Kimura, 1999, 2004; Baron-Cohen, 2003) consistently shows that males outperform females in "folk physics" - e.g., visuo-spatial and mathematical reasoning, while females generally are better at "folk psychology" - e.g., understanding of others' feelings and states of mind, empathy, social and communicative abilities.

In order to capture such sex differences in cognition, BaronCohen proposed a two-dimensional model: the typical male brain is higher in systemizing (i.e., the drive to analyze the variables in a system, to derive the underlying rules that govern its behavior and predict it), while the female brain is more geared toward empathizing (i.e., the drive to identify another person's emotions and thoughts, and to respond with appropriate emotions). Autisticlike traits represent a combination of high systemizing and low empathizing, an exaggerated form of the average sex differences in cognitive and neuropsychological structure (Baron-Cohen et al., 2005). In an evolutionary perspective, the typical male and female cognitive profiles are seen as adaptations to ancestral human lifestyles. High systemizing and low empathizing would have been especially adaptive for men, giving them advantages in hunting (e.g., improved way-finding, better trace and path following, tolerance of solitude) and tool-making. On the other hand, high levels of empathizing would have been especially adaptive for women, given the importance of empathy in kin relationships (including mothering) and in the management of complex social networks (Baron-Cohen, 2003). Despite substantial overlap, systemizing and empathizing are not identical to the mechanistic and mentalistic dimensions proposed by Crespi and Badcock (2008a). In particular, in Baron-Cohen's model empathizing is always accurate by definition, since it implies the ability to correctly identify others' mental states and respond with appropriate emotions. As a consequence, Baron-Cohen sees the "extreme female brain" as basically nonpathological (Baron-Cohen, 2003), while Crespi and Badcock treat psychosis as a pathological, hyper-mentalistic phenotype coupled to deficitary mechanistic cognition.

Baron-Cohen's theory is supported by a remarkable amount of empirical data. First, the incidence of AS and high-functioning autism is highly male-biased (upto 10:1; Baron-Cohen, $1999,2002)$. Second, the performance of people in the autisticspectrum lies at the male-typical extreme of cognitive abilities: for example, autistics do better than control males in visuo-spatial tasks in which males outperform females (Jolliffe and BaronCohen, 1997). At the same time, they lag behind typical males in the development of female-biased abilities, such as language and social skills (Baron-Cohen et al., 1999). Furthermore, studies of fetal testosterone (fT) indicate that exposure to higher androgen levels in utero increases the likelihood of developing high-systemizing cognitive profiles, beyond the effect of sex per se (Auyeung et al., 2006, 2009). Even in newborns, prenatal fT levels correlate negatively with eye contact, and positively with attention toward mechanical and spatial stimuli (Lutchmaya et al., 2002; Kimura, 2004). High fT levels also predict lower quality of 
social relationships and restricted interests (Knickmeyer et al., 2005), and may affect the sex-typical patterns of play behavior (Knickmeyer et al., 2008).

It should be noted that, despite the evidence just presented, the relationship between $\mathrm{fT}$ levels and autistic-like traits is still debated and may turn out to be more complex than proposed by BaronCohen and colleagues. For example, Voracek and Dressler (2006) found no correlation between fT indicators and Baron-Cohen's empathizing and systemizing measures in a non-clinical sample; and as noted by De Bruin et al. (2006), high fT levels are also found in other developmental disorders (such as ADHD and oppositionaldefiant disorder), so they can hardly be considered a specific risk factor for autism. Baron-Cohen's emphasis on sex hormones may also underestimate the role of other sex-linked genetic factors; for example, Marco and Skuse (2006) and Skuse (2005) proposed that $\mathrm{X}$-linked genes may be involved in the etiology of autistic-spectrum symptoms in various genetic disorders, and that some of them may show imprinted expression patterns.

\section{AUTISM AND FITNESS INDICATORS}

In a recent paper, Shaner et al. (2008b) advanced the hypothesis that, just like psychosis, autism represents the negative form of a fitness indicator. In contrast with psychosis, however, the fitness indicator in question would be not sexually but parentally selected: children have evolved to display their genetic quality to parents in order to effectively solicit their investment (especially in the context of sibling rivalry), and complex children's behaviors (for example, social responsiveness, social engagement and "theory of mind") could function as costly and sensitive fitness indicators.

Whereas the hypothesis is plausible (see also Miller, 2000a,b) and helps explain the early emergence of autistic symptoms, we believe it also has a number of weaknesses in its present form. For example, the authors speculate that parental selection on infants' and children's "charm" may be directed to some of the same traits that will later affect the child's attractiveness as a mate (which is to be expected, given that - by definition - fitness indicators signal good genes and low mutation load). However, this would imply that - at least in some cases - the same genetic variants should predispose both to autism and to psychotic-spectrum disorders. A strong version of this thesis would have autistic children later experiencing an increased risk of becoming schizophrenic, which does not seem to be the case (Crespi and Badcock, 2008b). In addition, the hypothesis has trouble explaining the enhanced cognitive abilities of people with Asperger and high-functioning autism (e.g., their visuo-spatial and systemizing skills). Shaner and colleagues hypothesized that they may reflect "compensatory hypertrophy" of the spared abilities during brain development, but this interpretation appears somewhat post-hoc, especially in view of the fact that moderate autistic-like traits are associated with talent in normal individuals (Happé and Vital, 2009).

In conclusion, we believe that the hypothesis put forth by Shaner and colleagues is intriguing but still problematic. In its present version, it stands in direct conflict with our own hypothesis, but further theoretical refinements in one or both hypotheses may ultimately render them compatible. For example, the hypothesis by Shaner and colleagues may explain a proportion of pathological cases better than the normal, non-clinical variation in autistic-like traits; or it may turn out that parents can be sensitive to more than one type of fitness indicator (in addition to indicators of children's reproductive strategy-related traits) and shift their preferences depending on their own reproductive strategy and the local environment. Fortunately, both hypotheses can be used to generate testable predictions: first, we conform to Crespi and Badcock's model in predicting that paternally expressed genes should increase autistic-like traits (see Sexual Selection and the Imprinted Brain Theory), while Shaner et al. (2008b) argued the exact opposite, i.e., that maternally expressed imprinted genes should increase the risk for developing autism. Second, our hypothesis entails direct selection on alleles that favor autistic-like traits (while not on autistic disorders per se), while Shaner and colleagues argue that selection should have favored alleles that enhance the sensitivity of the fitness indicator, with autistic-like traits being just the "side effect" of high mutation load on a sensitive genetic background. The two hypothesis also generate different predictions concerning the epidemiology of autism and psychosis (see Conclusion).

\section{VARIABILITY IN HUMAN REPRODUCTIVE AND MATING STRATEGIES}

In this paper we argue that the evolution of autistic-like and schizotypal traits has been shaped - at least in part - by their opposite effects on reproductive and mating strategies. In this section, we briefly review the basic concepts of life history theory and the main evolutionary approaches to human mating. Current theories of human reproduction and mating emphasize the adaptive nature of strategic diversity: no single strategy can be the best regardless of context, and reproductive success can be reached by different paths - often involving dramatically different solutions to the allocation problems described by life history theory.

\section{LIFE HISTORY STRATEGIES, MATING, AND PARENTING}

Life history theory is a framework for the evolutionary analysis of the survival and reproduction patterns that define an organism's life course (see Hill, 1993; Kaplan and Gangestad, 2005; Ellis et al., 2009). Life history theory models the allocation of resources to competing developmental tasks during an organism's lifetime; since metabolic resources and time come in finite amounts, a number of trade-offs arise. The most basic life history trade-off pits somatic effort, i.e., resource investment in growth, body maintenance, and learning, versus reproductive effort, i.e., resource investment in reproduction. Reproductive effort can be further partitioned into mating effort and parenting effort; the former refers to obtaining and retaining sexual partners, while the latter refers to enhancing the survival of already existing offspring and other genetic relatives at a cost to the parent's immediate benefits. Resolution of these trade-offs constitutes an organism's life history strategy or reproductive strategy, and selection favors strategies that maximize the long-term fitness outcomes of the organism's reproductive decisions. Reproductive strategies can thus be conceived as suites of co-evolved anatomical, physiological, and psychological traits designed for the optimal allocation of resources among competing developmental tasks.

Since the costs and benefits of a given strategy vary as a function of the local ecology (e.g., mortality risk, predictability of the environment, resource availability, pathogen prevalence) and 
individual characteristics (e.g., size, genetic quality, and so on), life history strategies usually show remarkable within-species variation and at least some amount of developmental plasticity (Hill and Kaplan, 1999; Ellis et al., 2009). Another crucial factor affecting within-species variation in reproductive strategies is sex: usually, males invest more in mating effort and less in parenting effort than females do, and tend to develop slower than females (a form of somatic effort) in order to reach an optimal level of competitive ability (Trivers, 1972; Kokko and Jennions, 2008). Humans show a peculiar pattern compared to the other great apes (and mammals at large), in that their strategic repertoire includes the possibility of extended parental care by fathers. However, human paternal investment is highly facultative; it varies between cultures, groups and individuals, depending on ecological (e.g., mortality risk, unpredictability), sociocultural (e.g., polygynous versus monogamous mating systems) and genetic factors (see Geary, 2000, 2005; Marlowe, 2003; Figueredo et al., 2004; Quinlan, 2008; Del Giudice, 2009).

\section{MEN'S AND WOMEN'S MATING STRATEGIES}

Mating strategies can be described as the psychological and behavioral patterns involved in choosing, locating, courting, and retaining a mate. As such, they represent a component of reproductive strategies, primarily dealing with the regulation of the mating versus parenting trade-off. The human mating system shows remarkable flexibility, and both men and women possess a wide set of mating strategies including short- and long-term mating, extra-pair copulations, and serial mating (Gangestad and Simpson, 2000; Greiling and Buss, 2000; Buss, 2003, 2007).

Early attempts at charting the domain of human mating emphasized the average differences between typical male and female strategies (Buss, 1989; Buss and Schmitt, 1993). Men express greater desire for short-term mates than women, and prefer a larger number of sexual partners; in addition, men and women differ in how they weigh physical attractiveness (indicative of fertility and/or good genetic quality) versus social status and the ability/ willingness to secure and provide resources. More recently, evolutionary theorists have focused on the adaptive benefits of flexible, conditional strategies in both sexes (Gangestad and Simpson, 2000). Although average sex differences in mating clearly exist, both men and women adaptively calibrate their strategies and mate preferences according to local ecological conditions and personal characteristic. In the strategic pluralism model by Gangestad and Simpson, women's mate preferences depend on the specific mating strategy they are pursuing at a given time, which in turn can be influenced by many factors including pathogen prevalence (Gangestad and Buss, 1993), resource availability, local sex ratio (e.g., Stone et al., 2007), menstrual cycle phase (e.g., Pillsworth et al., 2004), and age (e.g., Kenrick and Keefe, 1992).

When engaging in short-term mating strategies, women should be attracted by good genes indicators - such as physical attractiveness, masculinity, body and facial symmetry, verbal intelligence, creativity, and dominance (e.g., Miller, 2000b; Haselton and Gangestad, 2006; Frederick and Haselton, 2007; Gangestad et al., 2007; Kaufman et al., 2007). On the other hand, women oriented toward long-term relationships should be interested in finding mates who can provide material benefits and who show the potential for good parental investment; they should also be attracted by cues of future resource acquisition, e.g., ambition or good career prospects (Buss and Schmitt, 1993), and by cues of commitment and willingness to invest.

\section{A SEXUAL SELECTION HYPOTHESIS}

We are now ready to advance an integrative sexual selection hypothesis on the evolution of autistic-like and schizotypal traits. Our hypothesis can be summarized as follows:

1. In addition to their general relation with mentalistic and mechanistic skills, autistic-like and schizotypal traits have important effects on mating-related behavior. The evolution of both autistic-like and positive-schizotypal traits has been driven - at least in part - by sexual selection through mate choice, because of the opposing effects of these traits on individual reproductive and mating strategies.

2. In particular, positive-schizotypal traits favor mating-oriented strategies based on good genes display (as theorized by Nettle and Miller), whereas autistic-like traits can be adaptive in the context of parenting-oriented strategies based on long-term resource allocation and reduced mating effort.

3. The asymmetric sexual selection pressures on human males and females may contribute to explain the distinct patterns of sex-related incidence of autism and psychosis. In particular, autistic-like personality traits should have undergone stronger sexual selection in males than in females, given the stronger female preference for reliable cues of paternal investment.

\section{SEXUAL SELECTION FOR POSITIVE SCHIZOTYPY: HIGH-MATING EFFORT AND GOOD GENES DISPLAYS}

As discussed earlier, mating-related models of schizotypy converge on the proposition that positive-schizotypal traits may work as sensitivity enhancers of sexually selected fitness indicators, possibly through their effects on verbal and artistic creativity. This would render them adaptive for individuals pursuing mating-oriented strategies that depend on good genes displays, as suggested by Shaner et al. (2008a). When competing for short-term mating, "amplifying" the indicators of one's genetic and environmental quality maximizes the chances of achieving outstanding mating success in both sexes; but it also increases one's risk of psychosis, which would result in drastically reduced mating opportunities. High positive schizotypy thus constitutes a high-risk strategy, and we should expect to find it in males more often than in females despite the fact that positive schizotypy is, on average, larger in females. This consideration casts new light on the idea that autism is the manifestation of an "extreme male brain;" from the vantage point of mating strategies, high-schizotypy phenotypes may be almost as male-typical as autistic-like ones, even if embodying a totally different kind of strategy.

\section{SEXUAL SELECTION FOR AUTISTIC-LIKE TRAITS: LOW-MATING EFFORT, HIGH PARENTAL INVESTMENT AND LONG-TERM RESOURCE ALLOCATION}

We propose that autistic-like traits in the non-clinical range provide reproductive advantages through a number of behavioral effects that contribute to attractiveness in the context of parenting-oriented 
reproductive strategies. For this reason, autistic-like traits can be expected to undergo sexual selection through mate choice, especially in ecological and social contexts favoring long-term mating and high levels of paternal investment. The stronger female preference for cues of paternal investment would lead to stronger sexual selection in males, thus contributing to the sex-biased expression of autistic-like traits. We are not arguing, however, that autistic-like traits have originated by means of sexual selection; both autistic-like traits and their sexually differentiated expression have probably evolved for reasons unrelated to mating, as theorized for example by Baron-Cohen (2003). In this section we will explore the effects of autistic-like traits on mating and reproductive strategies.

First of all, high-autistic-like traits are likely to lead to diminished motivation and opportunity for short-term mating relationships with multiple partners. The smaller social networks of individuals with autistic-like personalities, together with their low extraversion and openness to experience (Austin, 2005; Wakabayashi et al., 2006), predict reduced interest in novelty (including sexual novelty) and fewer opportunities to interact with potential mates. Indeed, low extraversion and openness have been found to correlate with fewer sexual partners (Nettle, 2005; Miller and Tal, 2007). Individuals high in autistic-like traits also lack the verbal/artistic creativity that seems to partly mediate the effects of positive schizotypy on mating success, although they may be quite creative in the technical and/or scientific sense. In human societies, men with autistic-like personalities can gain status not by direct social manipulation but rather by attaining "cultural success," that is, by developing and mastering culturally valued technical or cognitive skills (see Baron-Cohen, 2003; Spikins, 2009).

Autistic-like traits would thus result in a reduced number of partners and, possibly, later initiation of sexual relationships; when already mated, individuals high in autistic-like traits can be expected to be more faithful than average and to be at lower "risk" of engaging in extra-pair relationships. Consistent with this set of expectations, Jobe and White (2007) found that, among undergraduates, AQ scores predicted shorter duration of friendships but longer duration of romantic relationships. Relational stability and faithfulness are considerable assets when implementing a slow, high-parenting strategy, and should be deemed attractive by potential romantic partners interested in monogamous, long-term relationships. Importantly, cues of relational stability and protracted investment are much more relevant to female mate choice; thus, autistic-like traits can be expected to be higher in males, due to sexual selection by females for low-mating, high-parenting strategists.

Relational stability is, however, only the first step toward actual parental investment; a desirable long-term partner should also possess sufficient resources, and be willing to invest them in the relationship. Crucially, there are several reasons why autistic-like traits may increase resource acquisition and retention in both ancestral and modern societies, further contributing to a behavioral profile well adapted to high-parenting male reproductive strategies. These can be grouped in three categories: (1) hunting/technical abilities, (2) behavioral persistence, and (3) low-mating-related resource consumption. The increased visuo-spatial and systematic reasoning abilities associated with autistic-like traits (Baron-Cohen et al., 2009; Grinter et al., 2009) are highly advantageous in at least two crucial human activities: hunting and tool-making. Indeed, the case has been often made that the average male superiority in certain cognitive tasks derives from selection on hunting prowess and tool-making abilities (e.g., Silverman and Eals, 1992; BaronCohen, 2003). Hunting and tool-making are instrumental to food provisioning and, despite vigorous debate in evolutionary anthropology, both evidence and mathematical models indicate that hunting has been an important form of parental investment in our evolutionary history (e.g., Bock, 2002; Kaplan and Robson, 2002; Kramer, 2005; Gurven and Walker, 2006; Winking et al., 2007; Gurven and Hill, 2009). Meat provision by males, combined with extensive cross-generational resource transfer (i.e., protracted parental investment), may actually have been a crucial factor in the evolution of our slow developmental timing and oversized brain (Kaplan et al., 2000; Geary and Flinn, 2001; Flinn and Ward, 2005). In addition to hunting-related abilities, autistic-like traits include single-mindedness, low distractibility, high involvement in the current task, attention to details, and strong interests of nearly obsessive intensity. Again, while these characteristics may do little to make one stand out in some forms of social interaction, they can dramatically increase one's effectiveness in tasks that require persistence and protracted effort, including hunting, tool-making, and gathering of information about one's physical environment. All of these traits go in the direction of facilitating resource acquisition.

Third, the reduced mating effort that should be associated with autistic-like traits would, by itself, contribute to increase resource retention. Successful courtship requires considerable resource investment by males (including time, energy, and cognitive effort in addition to material resources); a recent study by Kruger (2008) has empirically documented a positive relation between mating effort (i.e., the number of actual and desired sexual partners) and financial consumption in US men (but not women). Of course, resource retention becomes an especially important trait in post-agricultural societies where resources can be preserved and accumulated. Even in hunter-gatherer societies, mating-related consumption of resources, time, and energy can detract from a young adult's investment in the welfare of his natal family members and (later) of his own mates and children.

The above suggests that individuals relatively high in autistic-like traits should exhibit a range of behavioral characteristics leading to reduced mating effort, increased resource acquisition, and better resource retention. These characteristics are valuable to women in search for a long-term partner, and may more than offset the corresponding reduction in social abilities experienced by individuals with autistic-like traits. In fact, reduced social abilities and empathy are instrumental to the low-mating phenotype we are describing, as long as males can employ their social, empathic and communicative skills as effective courtship tools (Miller, 2000b). A socially unremarkable man may still be a valuable husband, especially if he is likely to be faithful, good at acquiring resources, and willing to invest those resources in his wife and offspring. This consideration brings us to the last step toward paternal investment, that is, the willingness to invest resources in a stable couple relationship and, eventually, in the couple's offspring.

As yet, there have been no studies investigating whether autistic-like traits predict investment in partners and children; based on our hypothesis, we made the counterintuitive prediction that autistic-like traits should correlate with higher investment 
levels, and confirmed it in a sample of 199 young adults (see An Empirical Test). Our proposal that individuals with autistic-like personalities can become desirable long-term partners is reinforced by a recent study by Pollmann et al. (2009). These authors found that autistic-like traits in married people have no effect on the spouse's relationship satisfaction - that is, partners of people with autistic-like personalities are on average just as satisfied as those of people low in autistic-like traits.

\section{Did selection for autistic-like traits increase in the Holocene?}

When researching human psychological adaptations, it is customary to consider an environment of evolutionary adaptiveness (EEA) extending until the beginning of the upper Pleistocene, about 100,000 years ago. However, the accumulating evidence of strong recent selection in the human genome (e.g., Voight et al., 2006; Hawks et al., 2007) indicates that, especially when theorizing about simpler adaptations (such as quantitative variation in personality), it may be appropriate to consider how selection pressures changed in more modern environments. Here we suggest that the changes in life conditions brought about by agriculture may have determined increased selection on autistic-like traits during the last 10,000 years. Indeed, it has even been hypothesized that the social integration of individuals high in autistic-like traits has been a crucial step toward human modernity. Autistic-like personalities are especially likely to produce technical and cultural innovations, and the archeological record of the upper Pleistocene is consistent with a rising influence of "technologically minded" individuals on cultural practices and information transmission (Spikins, 2009). The increasing importance of technology and systematic reasoning during and after the agricultural revolution would have done nothing but intensify this trend; moreover, the increased opportunity for resource accumulation and inter-generational transfer afforded by agriculture should have made long-term allocation even more adaptive in the context of protracted parental investment.

Among the most active researchers working in this perspective are Cochran and Harpending (2009); see also Harpending and Cochran (2002). These authors made a strong case that the transition to agriculture has been responsible for a host of new selection pressures, rapidly altering many aspects of human physiology and psychology and driving a major acceleration of human genetic evolution. Farming populations have undergone adaptive changes in food metabolism (e.g., lactose tolerance, modified carbohydrate assimilation) and in immune functioning (e.g., increased defense against infectious diseases); crucially, changes in personality traits may have occurred as well, and some behavioral phenotypes or strategies may have become more strongly adaptive in post-agricultural societies compared with hunter-gatherer societies. Cochran and Harpending (2009) argued that the following traits have probably been selected for because of their adaptive effects in farming populations: (1) the ability to defer gratification, (2) the propensity for sustained work and resource accumulation, (3) a relatively high level of selfishness and a reduced motivation to share (at least compared with freely-sharing hunter-gatherers), and (4) a set of cognitive abilities useful in trading and resource exchange, such as complex mental-model building and mathematical skills (see Cochran and Harpending, 2009, for detailed discussion). Collectively, these traits describe a "bourgeois personality," predisposing males to the high degree of biparental investment that is vital in most agricultural ecologies (see Quinlan, 2008). We are struck by the overlap between Cochran and Harpending's bourgeois personality and our autistic-like phenotype; if these authors are correct, autistic-like traits may have been subject to recent positive selection in postagricultural populations.

\section{SEXUAL ASYMMETRIES}

Sexual selection for the kind of long-term, high-investment strategy we associate with autistic-like traits should have been especially strong in males, given the stronger female preference for resource holding potential and cues of paternal investment. This does not mean that autistic-like traits are selected against in females - only that there are reasons to expect a stronger asymmetry in their sex-related distribution. Such asymmetry is consistent with the extremely sex-biased incidence of autism-spectrum syndromes compared with the more balanced pattern of schizophrenia. As we already noted, however, sexual selection is only one of the factors that can influence the sex distribution of autistic-like and schizotypal traits. For example, female social relationships (both cooperative and competitive) generally require a higher amount of mentalistic reasoning (Geary, 1998; Geary et al., 2003), so that hyper-mentalistic traits may have been selected in females also for reasons unrelated to mate choice (Crespi and Badcock, 2008a,b).

As extensively discussed in the evolutionary literature, there is a lot of within-sex variation in human reproductive and mating strategies; autistic-like and schizotypal phenotypes certainly do not exhaust the range of available strategic options. For example, there are probably several alternative pathways to sustained paternal investment in men, some of which may be related to autistic-like traits while others may depend on secure attachment and the associated need for closeness, intimacy, and long-term bonding (see Kirkpatrick, 1998; Simpson and Belsky, 2008; Del Giudice, 2009). In securely attached men, high paternal investment is associated with well-developed social and interpersonal skills; if our hypothesis was correct, men with autistic-like personalities would show a different pattern - one characterized by high parental investment but relatively limited interpersonal skills. Another specialized, male-biased phenotype we have not considered here is that of psychopaths, who may be enacting a kind of high-mating strategy based on interpersonal deception and sexual coercion (Mealey, 1995; Harris et al., 2007).

Because of such heterogeneity in reproductive and mating strategies, it is reasonable to expect the average sex difference in autistic-like traits to be relatively small, even if most high-autistic individuals are in fact males. A closer look at the distribution of AQ scores in non-clinical participants (e.g., Figure 2 in Baron-Cohen et al., 2001) clearly reveals that males are disproportionately represented at the high end of the scale, whereas the proportions of males and females are much more similar in the low AQ range. As a result, the means of the two sexes are relatively close to one another even though high-autistic individuals are mostly males. Similar considerations apply to positive schizotypy: whereas women score higher than men on average, suggesting some degree of female selective advantage, high-schizotypal men have a chance to be remarkably successful in mating - even at the cost of increased risk of psychosis. 
Thus, the male distribution may turn out to be more skewed than the female one, with many low-schizotypal men and a minority of men with very high positive schizotypy scores.

Finally, Archer and Mehdikhani (2003) used parental investment theory to predict that sexually selected traits should be more variable in men compared to women, based on the higher facultativeness and variability of male investment patterns; they found support for their hypothesis with respect to several traits including physical aggression, mate preferences, and spatial-quantitative abilities. If our hypothesis was correct, we should observe greater male variability in both autistic-like and schizotypal traits, as well as a prevalence of males at the high end of both dimensions. Both these predictions were confirmed in our sample of young adults (see An Empirical Test).

\section{SEXUAL SELECTION AND THE IMPRINTED BRAIN THEORY BIPARENTAL CARE AND THE GENERALIZED KINSHIP THEORY}

The original kinship theory of imprinting depends on the assumption that the mother is the only provider of parental investment, i.e., on the assumption of strictly uniparental care. Whereas this investment pattern characterizes more than $90 \%$ of all mammals, there are several mammalian species (humans included) in which fathers provide investment in the form of food, time, and expended energy. Recently, Úbeda (2008) extended the kinship theory of imprinting to deal with biparental investment patterns; his analysis has remarkable implications, and is especially relevant to our present hypothesis. In the classic framework, paternally expressed genes always increase resource transfer toward the offspring, while maternally expressed genes always reduce it. When both parents invest, however, more complex expression patterns can arise, with the most interesting cases being those where paternal investment increases over time relative to maternal investment. This shifting investment pattern is observed in biparentally caring mammals, where the mother is the primary provider during gestation and lactation, and paternal provisioning increases after weaning. The same general pattern is thought to characterize humans: paternal provisioning has been specifically linked to the extended growth period of human children and juveniles, and men can contribute quite a lot to the welfare of their adult sons and daughters, the more so since agriculture allowed for unprecedented degrees of resource accumulation. This is not to say, of course, that all men contribute equally to parental care; see for example Geary (2005) and Quinlan (2008) for discussion of human paternal investment as a facultative adaptation.

When relative paternal investment increases over time relative to maternal investment, imprinted genes are expected to reverse their expression or imprinting status at different stages of development. Importantly, reversal is expected even if paternal investment always remains lower than maternal investment in absolute terms. If weaning is taken as a developmental marker of increased paternal investment, one can predict the evolution of two general patterns (Úbeda, 2008): (1) two different genes, both increasing resource transfer, are expressed at different times: the gene expressed before weaning is paternally expressed, while the one expressed after weaning is maternally expressed; (2) a single gene increasing resource transfer is expressed across developmental stages, but its imprinting status shifts after weaning from maternally to paternally expressed. The opposite sequence is predicted for genes reducing resource flow. A third pattern is also possible; (3) a single paternally expressed gene that increases resource transfer before weaning but reduces it after weaning, or a maternally expressed gene that decreases resource transfer before weaning but increases it after weaning.

In summary, the paternal genome should favor increased resource transfer early in development (when paternal investment is relatively low), but reduced resource transfer at later stages (when paternal investment increases); the maternal genome should favor the opposite pattern. This biphasic conflict model accounts for a puzzling feature of Prader-Willi syndrome (PWS), a disorder resulting from loss of some paternally derived genes on chromosome 15 and, consequently, from maternal over-expression: whereas infants with PWS show poor suckling and reduced growth before weaning (two indicators of inhibited resource demand), they later become exceedingly hungry, and often obese. Thus, paternally and maternally expressed genes in human may show opposite effects on resource transfer in early and later development (see Úbeda, 2008 for detailed discussion and Haig, 2010 for an alternative perspective).

\section{MATING STRATEGIES, RESOURCE FLOW, AND THE IMPRINTED BRAIN}

The generalized kinship theory of imprinting (henceforth GKT) provides a fascinating connection between our sexual selection hypothesis and the imprinted brain theory of autistic-like and schizotypal traits. The connection lies in the effects of an individual's reproductive and mating strategy on his/her pattern of resource demand in adolescence and early adulthood. The mating effort associated with positive schizotypy is likely to increase resource demands on parents. In females, early childbearing (especially in the context of short-term mating) usually imposes additional investment costs on parents and close kin. In males, high-mating effort usually involves conspicuous resource consumption and a focus on short-term benefits rather than on long-term accumulation (Kruger, 2008); for young males, the needed resources may often be supplied by parents. Even in ecologies that do not support resource accumulation, mating behavior contributes to the flow of resources within the family: adolescent offspring who are not engaging in courtship can employ their time and energy to forage and/or help parents with other subsistence-related tasks, thus giving a net contribution to the family balance. Thus, a son or daughter engaging in high (and early) mating effort is a likely source of increased costs for parents; moreover, these costs are going to be paid for sooner, thus exacerbating the conflict of interest between parents and offspring about resource allocation (i.e., fertile parents can invest resources in producing and raising more children). Given that courtship is generally a more costly activity for males than it is for females, positive-schizotypal sons may be especially investment-demanding for parents. On the other hand, the autistic-like phenotype we have described is characterized by low-mating effort, delayed reproduction, and resource retention/ accumulation; particularly in males, this profile should translate into reduced investment demands on parents during adolescence and early adulthood.

Following the logic of the GKT, genes contributing to the development of autistic-like traits can be predicted to become paternally expressed in the course of evolution, whereas genes contributing 
to positive schizotypy should become maternally expressed. Thus, the original evolutionary drive favoring the imprinted expression of autistic-like and schizotypal traits may have been provided by their effects on parental investment in late development. Later, the same genes could have acquired pleiotropic effects of the opposite sign on early resource transfer (e.g., fetal and neonatal growth). As a result, genes contributing to autistic-like traits would increase resource transfer early in development (from conception to early childhood) but reduce resource transfer as the child approaches sexual maturity; the opposite pattern would be expected from genes contributing to schizotypal traits. Alternatively, the association between autism-spectrum disorders, psychosis-spectrum disorders and early growth patterns might be explained by co-expression or linkage between different imprinted genes from the same parent. While other evolutionary-genetic scenarios are certainly possible, the effect of offspring mating on resource transfer represents a crucial theoretical link between sexual selection and the evolution of imprinted gene expression in humans. Consistent with our hypothesis is initial (if incomplete) evidence that maternally expressed genes tend to accelerate sexual maturation in prepubertal children (Haig, 2010).

Intriguingly, empirical findings exist which lend support to the GKT as applied to autistic-spectrum disorders. Whereas autism and AS are associated with high birth weight and faster growth in early development (reviewed in Crespi and Badcock, 2008a), children and adolescents with AS tend to be underweight (Hebebrand et al., 1997). This finding has been replicated by Sobanski et al. (1999), whose young AS patients often fell in the lowest percentiles of the normal BMI distribution. This biphasic growth pattern is the exact opposite of that observed in PWS, and is consistent with the reversal of imprinted genetic effects predicted by the GKT.

\section{Patterns of genetic correlation}

Our hypothesis has the advantage of bridging sexual selection with the kinship theory of imprinting, but - predictably - it also introduces some additional complications. In particular, Úbeda (2008) derived the GKT under the assumption that imprinted genes only affect offspring resource demands, whereas in our theory genes for autistic-like and schizotypal traits have a simultaneous effect on offspring demands and on parental reproductive strategies. As a result, complex patterns of genetic parent-offspring coadaptation (Kölliker and Richner, 2001) are predicted to arise. Under our hypothesis, individuals expressing a (maternally derived) "schizotypal allele" show reduced demands in early development but heightened demands at later stages. They also have a 50\% chance that their mother also expresses the same allele (depending on whether the mother has inherited the allele from her own mother or father), which should reduce maternal investment by promoting a mating-oriented reproductive strategy. Thus, the genetic correlation between offspring demand and maternal provision should shift from a positive one in early development to a negative one in older children and adolescents.

In contrast, individuals expressing a (paternally derived) "autistic allele" show increased demands in early development but reduced demands at later stages, and they have a 50\% chance that their father will express the same allele, leading to increased paternal investment. In this case, the genetic correlation between offspring demand and paternal investment would shift from positive to negative as development proceeds. Both positive and negative genetic correlations between parental supply and offspring demand have been demonstrated in non-human animals (Kölliker et al., 2005; Smiseth et al., 2008), but extant models are not well equipped for dealing with complex patterns such as the one predicted here. An important task for future research will be to extend Úbeda's GKT to deal with genes that affect both offspring and parental phenotypes, and formally explore the implications of such cross-generational effects for the evolution of imprinted gene expression.

\section{Sexually differentiated expression of imprinted genes}

The evolutionary argument we presented suggests that the fitness costs and benefits of autistic-like and schizotypal traits may differ in the two sexes. As a result, the genes involved in the development of autistic-like and schizotypal phenotypes can be expected to show a certain degree of sexually differentiated expression. This could happen in at least two (non-exclusive) ways: (1) via sex chromosomelinked genes (e.g., there may exist X-linked imprinted genes that predispose to autism and/or schizotypy); and (2) via regulation of genetic expression by sex hormones (e.g., by inclusion of androgen response elements in the promoter region of an imprinted gene). Whereas imprinting patterns on the $\mathrm{X}$ chromosome may differ from the classical autosomal case, this expectation is potentially consistent with both Baron-Cohen's emphasis on prenatal exposure to testosterone and with recent evidence that X-linked genes may be implicated in the genesis of autistic-like traits (Skuse, 2005). Hormone-sensitive imprinted genes may also explain why high levels of $\mathrm{fT}$ appear to act in a relatively non-specific way, predicting autistic-like traits but also apparently unrelated behavioral syndromes such as ADHD (De Bruin et al., 2006; see above).

\section{AN EMPIRICAL TEST}

In Section "Sexual Selection for Autistic-Like Traits: Low-Mating Effort, High Parental Investment and Long-Term Resource Allocation" we advanced the prediction that autistic-like traits would be associated to lower mating effort, reduced interest in short-term sexual relationships, higher levels of investment in one's partner, and stronger commitment to long-term relationships; positive schizotypy should display the opposite pattern of effects. We also hypothesized that autistic-like traits and positive schizotypy would show higher variability in males, and that males would be over-represented at the high end of both dimensions (see Sexual Asymmetries). We set out to empirically test these predictions in a sample of young adults.

\section{MATERIALS AND METHODS Participants}

Participants were 200 heterosexual, unmarried Italian adults (100 females and 100 males), ranging from 21 to 35 years of age $(M=25.9$, $\mathrm{SD}=3.9)$. Sixty-two percent of the sample consisted of college students from various faculties (including psychology, engineering, medicine, law, architecture, and the humanities), while the remaining $38 \%$ of participants were workers and professionals. All participants had at least a high school diploma. One of the male participants had to be dropped from the sample because of severely incomplete data; the sample size for all the analyses was thus $N=199$. 


\section{Measures and variables}

Autism-spectrum Quotient (Baron-Cohen et al., 2001; Italian version by the University of Cambridge Autism Research Centre: http://www.autismresearchcentre.com). The AQ is a 50 -item self-report measure of autistic-like traits in normal IQ individuals. Whereas the original AQ employed dichotomized scoring, we followed current practice (e.g., Hoekstra et al., 2008) and preserved full four-point scores in order to maximize scale reliability. Psychometric studies (Hurst et al., 2007b; Hoekstra et al., 2008) suggest that the AQ can be adequately represented by two correlated factors: an attention to details factor and a so-called interpersonal factor (indexed by the other four AQ scales). In the present sample, the results of parallel analysis (PA) followed by principal axis factor analysis (PFA) of the five scales were highly consistent with the two-factor solution. Two scores were thus computed, one corresponding to the attention to details scale (AQ-detail; $\alpha=0.71$ ) and another one obtained by summing the remaining scales (AQ-interpersonal; $\alpha=0.83$ ).

Schizotypal Personality Questionnaire (Raine, 1991; Italian version by Fossati et al., 2003). The SPQ is a 74-item self-report instrument for the measurement of schizotypal traits in the general population. Factor analyses of the SPQ by different investigators have yielded inconsistent results; while the two factors representing positive and negative schizotypy emerge reliably, three-factor solutions tend to differ widely among samples concerning the composition of the third factor (Raine et al., 1994; Bergman et al., 1996; Fossati et al., 2003). In the present sample, PA and oblique PFA with oblique rotation yielded a clear twofactor solution. Two scores were thus computed: SPQ-positive ( $\alpha=0.90$; Ideas of reference, Odd beliefs, Unusual experiences, Suspiciousness, Odd behavior, and Odd speech) and SPQ-negative ( $\alpha=0.84$; Excessive anxiety, No close friends, Constricted affect, and Suspiciousness).

Partner-Specific Investment Inventory (Ellis, 1998). The PSI Inventory is a 52-item questionnaire of emotional and material investment in romantic relationships. PSI items concern the time and resources expended in the present (e.g., "I pay for our evening entertainment") as well as behaviors promoting continued investment in the future (e.g., "When I talk about my future, my partner's always in it"). The self-report version of the PSI Inventory was employed (Tempelhof and Sabura Allen, 2008; Italian translation by the present authors); if a participant was not currently involved in a romantic relationship, he/she was instructed to think about the relationship with his/her last partner. In the original version of the questionnaire, scores are computed slightly differently for males and females using variable weights; in the present study, simple sums of standardized scales were computed in order to make male and female scores directly comparable. PA and PFA with oblique rotation carried out on the eight PSI scales suggested a theoretically interesting two-factor solution. The following scales loaded on the first factor: Expressive/nurturing, Giving of time, Honest, Socially attentive, and Not sexualizing of others; these scales all refer to behaviors that imply focusing on one's partner and keeping him/ her at the center of one's thoughts and attention. The other three scales (Future-oriented, Monetarily investing, and Good relationship with partner's family) loaded on the second factor; they indicate commitment and long-term investment in the relationship.
The factors were positively correlated (0.60). Accordingly, two separate scores were computed: PSI-focus $(\alpha=0.87)$ and PSIcommit $(\alpha=0.83)$.

Multidimensional Sociosexual Orientation Inventory (Jackson and Kirkpatrick, 2007; Italian translation by the present authors). The MSOI is a 21-item multidimensional measure of mating strategies, and it consists of three scales. The two attitude scales measure short-term mating orientation (STMO; $\alpha=0.93$ ) and long-term mating orientation (LTMO; $\alpha=0.89$ ). The STMO scale includes items such as "I can easily imagine myself being comfortable and enjoying casual sex with different partners," and "I believe in taking sexual opportunities when I find them;" the LTMO scale includes items such as "I hope to have a romantic relationship that lasts the rest of my life" and "I can see myself settling down romantically with one special person." The third scale is a measure of behavior $(\alpha=0.89)$ based on the self-reported total number of sexual partners, the number of casual sexual partners, and the number of sexual partners in the previous year.

\section{RESULTS}

\section{Descriptive statistics}

Descriptive statistics and zero-order correlations of the study variables are shown in Table 1. Variability was greater in the male group on nearly all measures. Male:female variance ratios (VR) ranged from 0.90 to 5.31 (mean $V R=1.73$; median $V R=1.28$ ). Figure 1 shows the relative distribution of males and females for total AQ scores and positive schizotypy (see Handcock and Morris, 1999). As predicted, males were over-represented at the high end of both scales; they were also over-represented at the low end of positive schizotypy. The male:female ratio was especially high at the upper extreme of autistic-like traits (about 2.6:1), with a less extreme male bias at the upper and lower extremes of positive schizotypy (about 1.6:1 and 1.4:1, respectively). This is a promising finding, and it would be extremely interesting to replicate it in a larger and more representative sample.

\section{The effects of autistic-like and schizotypal traits on mating strategies}

The contribution of autistic-like and schizotypal traits to individual variation in mating strategies was investigated by fitting structural equation models (SEM) to the data. The analysis was carried out as follows:

1. Based on theoretical considerations and inspection of the correlation matrix, two latent variables were modeled: mating effort (with MSOI-STMO and MSOI-behavior as indicators) and long-term investment (with MSOI-LTMO, PSI-focus and PSI-commit as indicators). The two latent variables were hypothesized to be negatively correlated due to unmeasured causes (e.g., a general life history factor); this association was modeled with correlated disturbances.

2. A number of associations between observed variables due to unmeasured causes were hypothesized on the basis of the empirical literature. Specifically, correlated variances and disturbances were modeled for the following pairs of variables: (1) positive and negative schizotypy, (2) the AQ-interpersonal and the AQ-detail scale, and (3) negative schizotypy and the AQ-interpersonal scale (see Correlations Between Autistic-Like 
Table 1 | Zero-order correlation matrix, means, and standard deviations of the study variables (untransformed scores). Correlations in the male subsample are shown below the diagonal, those in the female subsample above the diagonal.

\begin{tabular}{|c|c|c|c|c|c|c|c|c|c|c|}
\hline & 1 & 2 & 3 & 4 & 5 & 6 & 7 & 8 & 9 & 10 \\
\hline 1. Age & 1.00 & 0.01 & -0.31 & -0.35 & -0.33 & -0.01 & 0.24 & 0.04 & 0.20 & 0.15 \\
\hline 2. AQ-detail & 0.01 & 1.00 & 0.06 & 0.17 & 0.36 & 0.12 & 0.20 & -0.04 & 0.13 & 0.08 \\
\hline 4. SPQ-negative & -0.22 & 0.04 & 0.67 & 1.00 & 0.41 & 0.01 & -0.09 & -0.16 & 0.01 & -0.26 \\
\hline 5. SPQ-positive & -0.22 & 0.10 & 0.15 & 0.50 & 1.00 & -0.17 & -0.23 & 0.01 & -0.14 & 0.04 \\
\hline 8. MSOI-STMO & -0.06 & -0.04 & -0.11 & 0.06 & 0.24 & -0.41 & -0.43 & 1.00 & -0.47 & 0.57 \\
\hline 9. MSOI-LTMO & 0.13 & 0.13 & -0.03 & -0.15 & -0.16 & 0.47 & 0.42 & -0.41 & 1.00 & -0.24 \\
\hline 10. MSOI-behavior & 0.19 & 0.13 & -0.30 & -0.16 & -0.07 & -0.26 & -0.04 & 0.39 & -0.10 & 1.00 \\
\hline \multicolumn{11}{|c|}{ FEMALES $(N=100)$} \\
\hline$M$ & 26.0 & 23.7 & 78.5 & 7.6 & 12.6 & 4.2 & 0.2 & 30.8 & 43.5 & -0.4 \\
\hline
\end{tabular}

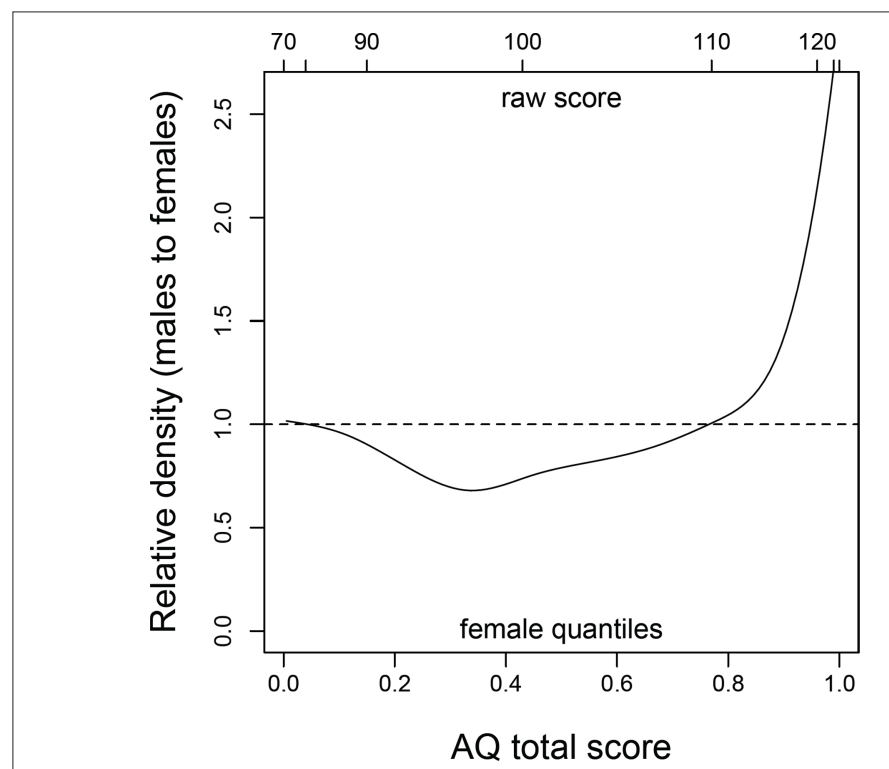

FIGURE 1 | Relative density plots (male:female ratio) of autistic-like and positive-schizotypal traits. Dashed lines indicate equal proportions of males and females. In both cases, males are over-represented at the high end of the

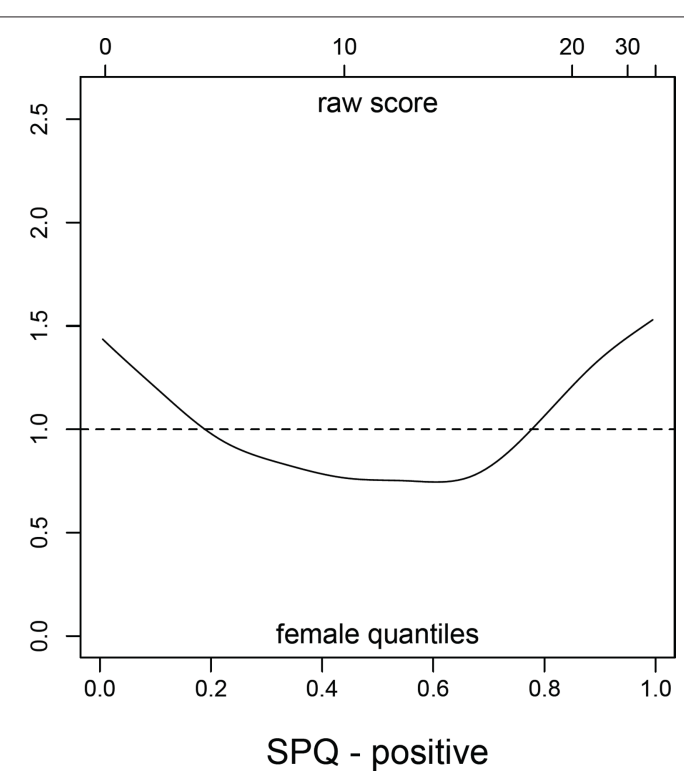

scale; males are also over-represented at the low end of positive schizotypy. Note: the lower $x$-axis shows the quantiles of the female distribution, while the upper $x$-axis shows the corresponding raw scores. and Schizotypal Traits). It should be noted that unmeasured causes also include shared method variance, e.g., similar item formulation in different scales.

3. A set of models was constructed predicting mating effort and long-term investment from autistic-like and schizotypal traits. The models were assembled by combining the following blocks: (a) the effects of AQ-interpersonal on mating effort and investment, (b) the effects of AQ-detail on mating effort and investment, (c) the effects of positive schizotypy on mating effort and investment, (d) the effects of negative schizotypy on mating effort and investment. The set also included a "null" model with no effects of either autistic-like or schizotypal traits.

4. Models were fitted to the covariance matrix using maximumlikelihood estimation, and compared using the small-sample version of Akaike's AIC $\left(\mathrm{AIC}_{\mathrm{C}}\right)$. After selecting the best model in the theoretically specified set described above, the effects of age and sex were added by empirical model respecification. This selection strategy combines a priori model specification (Burnham and Anderson, 2002) with a degree of exploratory 
analysis. The resulting model fit can be expected to be less than perfect; however, this strategy provides a more stringent test of the hypothesized model structure, and reduces the risk of capitalizing on chance (discussed in Burnham and Anderson, 2002).

Some of the variables (i.e., age, MSOI-LTMO, MSOI-behavior, PSI-focus, SPQ-positive and SPQ-negative) showed substantial departures from normality; since maximum-likelihood estimation is sensitive to distributional assumptions, these variables were log-transformed with added constants before model fitting in order to eliminate skew. Additionally, some of the variables were multiplied by appropriate constants to avoid ill-scaling of the covariance matrix. All statistical analyses were carried out in $\mathrm{R}$ 2.8.0 ( $\mathrm{R}$ Development Core Team, 2008) with the following packages: sem 0.9-13 (Fox, 2008), reldist 1.5-5 (Handcock, 2006), and psych 1.0-57 (Revelle, 2008).

The selected model is shown in Figure 2. Fit indices were satisfactory $\left(\chi_{(34)}^{2}=79.06, p<0.05\right.$; RMSEA $=0.081$; CFI $\left.=0.917\right)$. Females had lower AQ-interpersonal scores, but there were no sizable sex differences in schizotypy (again, it should be remembered that the present study was not based on a demographically representative sample). Sex also had direct effects on both mating effort $(\mathrm{F}<\mathrm{M})$ and long-term investment $(\mathrm{F}>\mathrm{M})$, thus confirming previous literature findings. Older participants had lower scores in schizotypy and in the interpersonal facet of autistic-like traits.

As hypothesized, autistic-like traits predicted reduced mating effort and higher long-term investment in romantic relationships. Interestingly, different facets of autistic traits appeared to contribute specifically to different aspects of mating strategies. In particular, AQ-interpersonal scores predicted reduced mating effort, whereas AQ-detail scores predicted increased long-term investment. On the contrary, positive schizotypy was negatively associated with long-term investment and positively associated with mating effort (Figure 2). Of special interest was the finding that, despite the substantial empirical overlap between the interpersonal facet of autistic-like traits and negative schizotypy, the latter had no independent effects on mating strategies. This finding underlines the need for improved, "cleaner" measures of schizotypal and autisticlike traits. It also strongly suggests that, even when investigating only one type of trait, the best procedure is to measure both autistic-like traits and schizotypy and model their unique effects after controlling for their statistical overlap.

\section{CONCLUSION}

In this paper we presented a new hypothesis on the evolution of autistic-like and schizotypal personality traits. Specifically, we explored the fitness-enhancing potential of autistic-like traits in the context of long-term mating strategies in humans, and advanced the hypothesis that both autistic-like and schizotypal traits have an evolutionary history of sexual selection through mate choice. We then proposed an intriguing connection between our sexual selection hypothesis and the dynamics of genomic imprinting, by recasting the imprinted brain theory in the context of the GKT. Our initial predictions concerning the effects of autistic-like and schizotypal traits on mating strategies were empirically supported, providing a first line of support to our argument and opening up a fascinating avenue for future research.

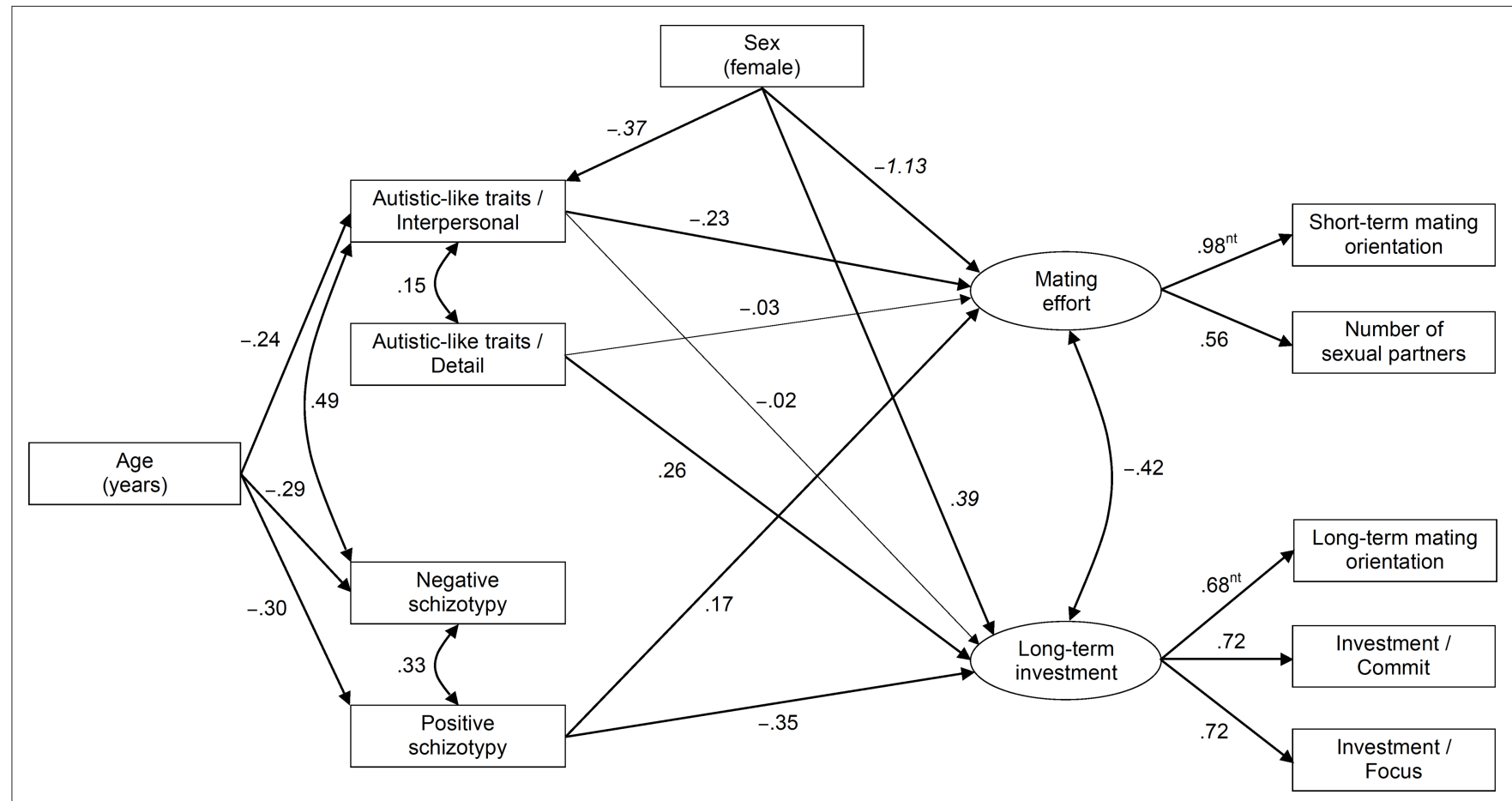

FIGURE 2 | Standardized path diagram of the selected model. For clarity of presentation, variances, disturbances, and measurement errors are omitted. The effects of sex (italicized) are reported as standardized differences between males and females $(d)$. Individual paths that were statistically significant in the unstandardized solution $(p<0.05)$ are drawn with thick lines. Legend: $\mathrm{nt}=$ not tested for significance (fixed loading). 
Another prediction that can be derived from our hypothesis concerns the epidemiology of autism and psychosis. We expect populations with traditionally monogamous mating systems and high paternal investment to show a lower incidence of psychosis (especially in males) and a higher incidence of autism. On the contrary, populations whose mating systems involve functional polygyny, reduced paternal investment and intense male-male mating competition should show a higher incidence of psychosis and a lower incidence of autism. Paternal investment and couple stability, rather than polygyny per se, are the key variables here; however, paternal investment is known to correlate negatively with polygyny at the cross-cultural level (Marlowe, 2000, 2003), so a correlation with polygyny may be expected - at least in traditional cultures. Whereas our predictions on the incidence of psychosis match those by Shaner et al. (2008a), the same authors predicted that autism should be more frequent in polygynous societies (Shaner et al., 2008b). Thus, cross-cultural epidemiological data could be used to discriminate between our hypothesis and that by Shaner and colleagues, although the possibility of recent selection pressures should invite caution about extending findings from foraging populations to modern, post-agricultural ones.

\section{REFERENCES}

Abu-Akel, A., and Bailey, A. L. (2000). The possibility of different forms of theory of mind. Psychol. Med. 30, 735-738.

Aleman, A., Kahn, R. S., and Selten, J. P. (2003). Sex differences in risk for schizophrenia: evidence from metaanalysis. Arch. Gen. Psychiatry 60, 565-571.

Archer, J., and Mehdikhani, M. (2003). Variability among males in sexually selected attributes. Rev. Gen. Psychol. 7, 219-236.

Austin, E. J. (2005). Personality correlates of the broader autism phenotype as assessed by the Autism spectrum Quotient (AQ). Pers. Individ. Dif. 38, 451-460.

Auyeung, B., Baron-Cohen, S., Ashwin, E., Knickmeyer, R., Taylor, K., and Hackett, G. (2009). Foetal testosterone and autistic traits. Br. J. Psychol. $100,1-22$.

Auyeung, B., Baron-Cohen, S., Chapman, E., Knickmeyer, R., Taylor, K., and Hackett, G. (2006). Foetal testosterone and the Child Systemizing Quotient (SQ-C). Eur. J. Endrocrinol. 155, 123-130.

Badcock, C., and Crespi, B. (2006). Imbalanced genomic imprinting in brain development: an evolutionay basis for the aetiology of autism. J. Evol. Biol. 19, 1007-1032.

Badcock, J. C., and Dragović, M. (2006). Schizotypal personality in mature adults. Pers. Individ. Dif. 40, 77-85.

Baron-Cohen, S. (1999). "The extreme male brain theory of autism," in Neurodevelopmental Disorders, ed. T.
Tager-Flusberg (Cambridge, MA:MIT Press), 401-429.

Baron-Cohen, S. (2002). The extreme male brain theory of autism. Trends Cogn. Sci. 6, 248-254. Difference. London: Penguin.

Baron-Cohen, S., Ashwin, E., Aswin, C., Tavassoli, T., and Chakrabarti, B. (2009). Talent in autism: hypersystemizing, hyper-attention to detail and sensory hypersensitivity. Philos. Trans. R. Soc. B 364, 1377-1383.

Baron-Cohen, S., and Hammer, J. (1997). Is autism an extreme form of the male brain? Adv. Infancy Res. 11, 193-217.

Baron-Cohen, S., Knickmeyer, R., and Belmonte, M. K. (2005). Sex differences in the brain: implications for explaining autism. Science 310 , 819-823.

Baron-Cohen, S., O'Riordan, M., Stone, V., Jones, R., and Plaisted, K. (1999). Recognizing of Faux Pas by normally developing children and children with Asperger syndrome or highfunctioning autism. J. Autism Dev. Disord. 29, 407-418.

Baron-Cohen,S., Wheelwright,S.,Skinner, R., Martin, J., and Clubley, E. (2001). The Autism-spectrum Quotient (AQ): evidence from Asperger syndrome/ high-functioning autism, males and females, scientists and mathematicians. J. Autism Dev. Disord. 31, 5-17.

Batey, M., and Furnham, A. (2008). The relationship between measures of creativity and schizotypy. Pers. Individ. Dif. 45, 816-821.

Bergman, A., Harvey, P. D., Mitropoulou, V., Aronson, A., Marder, D., Silverman,
Baron-Cohen, S. (2003). The Essential

Of course, our hypothesis is still largely speculative, and many strands of evidence (from genetics, development, neurobiology, psychopathology, and so on) will need to converge in order to fully confirm or disconfirm it. Additional theoretical work is also needed to fully understand the role of parental reproductive strategies in the evolution of imprinted genetic expression (see Sexual Selection and the Imprinted Brain Theory). We believe that our hypothesis holds considerable heuristic potential, and hope it will stimulate new lines of research on the behavioral and genetic correlates of autistic-like traits in the general population. In the process, we expect to gain many new insights in the structure of human personality, the function and development of individual differences, and the origin of psychological disorders.

\section{ACKNOWLEDGMENTS}

We wish to thank Christopher Badcock, Bruce Ellis, A. J. Figueredo, and Zachary Hohman for their useful comments on previous versions of the manuscript. Pietro Santoro and Rossella Costantino helped with data collection. This work was supported by the Regione Piemonte, bando Scienze Umane e Sociali 2008, L.R. n. 4/2006.

J., Trestman, R., and Siever, J. (1996). The factor structure of schizotypal symptoms in a clinical population. Schizophr. Bull. 22, 501-509.

Bock, J. (2002). Learning, life history, and productivity. Children's lives in the Okavango Delta, Botswana. Hum. Nat. 13, 161-197.

Brown, W. M., and Consedine, N. S. (2004). Just how happy is the happy puppet? An emotion signaling and kinship theory perspective on the behavioral phenotype of children with Angelman syndrome. Med. Hypotheses 63, 377-385.

Burnham, K. P., and Anderson, D. R. (2002).Model Selectionand Multimodel Inference: A Practical InformationTheoretical Approach, 2nd Edn. New York: Springer-Verlag.

Burt, A., and Trivers, R. (2006). Genes in Conflict. The Biology of Selfish Genetic Elements. Cambridge, MA: Belknap.

Buss, D. M. (1989). Sex differences in human mate preferences: evolutionary hypotheses tested in 37 cultures. Behav. Brain Sci. 14, 520-521.

Buss, D. M. (2003). The Evolution of Desire: Strategies of Human Mating, Revised 4 Edn. New York, NY: Basic Books.

Buss, D. M. (2007). The evolution of human mating. Acta Psychol. Sinica $39,502-512$.

Buss, D. M., and Schmitt, D. P. (1993). Sexual strategies theory: an evolutionary perspective on human mating. Psychol. Rev. 100, 204-232.

Claridge, G. (1997). Schizotypy: Implications for Illness and Health. Oxford, NY: Oxford University Press.
Claridge, G. S., McCreery, C., Mason, O., Bentall, R., Boyle, G., Slade, P., and Popplewell, D. (1996). The factor structure of 'schizotypal' traits: a large replication study. Br. J. Clin. Psychol. $35,103-115$.

Cochran, G., and Harpending, H. (2009). The 10,000 Year Explosion. How Civilization Accelerated Human Evolution. New York, NY: Basic Books.

Crespi, B., and Badcock, C. (2008a). Psychosis and autism as diametrical disorders of the social brain. Behav. Brain Sci. 31, 241-320.

Crespi, B., and Badcock, C. (2008b). The evolutionary social brain: from genes to psychiatric conditions. Behav. Brain Sci. 31, 284-296.

Crow, T. J. (2000). Schizophrenia as the price that Homo sapiens pays for language: a resolution to the central paradox in the origin of the species. Brain Res. Rev. 31, 118-129.

Davies, W., and Isles, A. R. (2008). Genomic imprinting and disorders of the social brain; shades of grey rather than black and white. Behav. Brain Sci. 31, 265-266.

Davies, W., Isles, A. R., and Wilkinson, L. S. (2005). Imprinted gene expression in the brain. Neurosci. Biobehav. Rev. 29, 421-430.

Davies, W., Lynn, P. M. Y., Relkovic, D., and Wilkinson, L. S. (2008). Imprinted genes and neuroendocrine function. Front. Neuroendocrinol. 29, 413-427. doi: 10.1016/j.yfrne.2007.12.001

De Bruin, E. I., Verheij, F., Wiegman, M. A., and Ferdinand, R. F. (2006). Differences in finger length ratio 
between males with autism, pervasive developmental disorder-not otherwise specified, ADHD, and anxiety disorders. Dev. Med. Child Neurol. 48, 962-965.

Del Giudice, M. (2009). Sex, attachment, and the development of reproductive strategies. Behav. Brain Sci. 32, $1-67$.

Dickins, B. J. A., Dickins, D. W., and Dickins, T. E. (2008). Is this conjectural phenotypic dichotomy a plausible outcome of genomic imprinting? Behav. Brain Sci. 31, 267-268.

Ellis, B. J. (1998). The Partner-Specific Investment Inventory: an evolutionary approach to individual differences in investment. J. Pers. 66, 383-442.

Ellis, B. J., Figueredo, A. J., Brumbach, B. H., and Schlomer, G. L. (2009). Fundamental dimensions of environmental risk: the impact of harsh versus unpredictable environments on the evolution and development of life history strategies. Hum. Nat. 20, 204-268.

Fernyhough, C., Jones, S. R., Whittle, C., Waterfhouse, J., and Bentall, R. P. (2008). Theory of mind, schizotypy, and persecutory ideation in young adults. Cogn. Neuropsychiatry 13, 233-249.

Figueredo, A. J., Vásquez, G., Brumbach, B. H., and Schneider, S. M. R. (2004). The heritability of life history strategy: the K-factor, covitality, and personality. Soc. Biol. 51, 121-143.

Flinn, M. V., and Ward, C. V. (2005). "Ontogeny and evolution of the social child," in Origins of the Social Mind: Evolutionary Psychology and Child Development, eds B. J. Ellis and D. F. Bjorklund (New York, NY: Guilford), 19-44.

Fossati, A., Raine, A., Carretta, I., Leonardi, B., and Maffei, C. (2003). The threefactor model of schizotypal personality: invariance across age and gender. Pers. Individ. Dif. 35, 1007-1019.

Fox, J. (2008). The SEM Package Version 0.9-13. Available at http://cran.rproject.org/

Frederick, D., and Haselton, M. G. (2007). Why is muscularity sexy? Pers. Soc. Psychol. Bull. 33, 1167-1183.

Gangestad, S. W., and Buss, D. M. (1993). Pathogen prevalence and human mate preferences. Ethol. Sociobiol. 14, 89-96.

Gangestad, S. W., and Simpson, J. A. (2000). The evolution of mating: trade-offs and strategic pluralism. Behav. Brain Sci. 23, 675-687.

Gangestad, S. W., Garver-Apgar, C. E., and Simpson, J. A. (2007). Changes in women's mate preferences across the ovulatory cycle. J. Pers. Soc. Psychol. $92,151-163$
Geary, D. C. (1998). Male, Female. The Evolution of Human Sex Differences. Washington, DC: American Psychological Association.

Geary, D. C. (2000). Evolution and proximate expression of human paternal investment. Psychol. Bull. 126, 55-77.

Geary, D. C. (2005). "Evolution of paternal investment," in The Evolutionary Psychology Handbook, ed. D. M. Buss (Hoboken, NJ: John Wiley \& Sons), 483-505.

Geary, D. C., Byrd-Craven, J., Hoard, M. K., Vigil, J., and Numtee, C. (2003). Evolution and development of boys' social behavior. Dev. Rev. 23, 444-470.

Geary, D. C., and Flinn, M. V. (2001). Evolution of human parental behavior and the human family. Parent. Sci. Pract. 1, 5-61.

Greiling, H., and Buss, D. M. (2000). Women's sexual strategies: the hidden dimension of extra-pair mating. Pers. Individ. Dif. 28, 929-963.

Grinter, E. J., van Beek, P. L., Maybery, M. T., and Badcock, D. R. (2009). Visuospatial analysis and self-rated autistic-like traits. J. Autism Dev. Disord. 39, 670-677.

Gurven, H., and Hill, K. (2009). Why do men hunt? A reevaluation of "Man the hunter" and the sexual division of labor. Curr. Anthropol. 50, 51-74.

Gurven, M., and Walker, R. (2006). Energetic demand of multiple dependents and the evolution of slow human growth. Proc. R. Soc. Lond. B $273,835-841$.

Haig, D. (1997). Parental antagonism, relatedness asymmetries, and genomic imprinting. Proc. R. Soc. Lond. B 264, 1657-1662.

Haig, D. (2000). The kinship theory of genomic imprinting. Annu. Rev. Ecol. Syst. 31, 9-32.

Haig, D. (2004). Genomic imprinting and kinship: how good is the evidence? Annu. Rev. Genet. 38, 553-585.

Haig, D. (2010). Transfers and transitions: Parent-offspring conflict, genomic imprinting, and the evolution of human life history. Proc. Natl. Acad. Sci. U.S.A. 107, 1731-1735.

Handcock, M. S. (2006). The Reldist Package Version 1.5-5. Available at http://cran.r-project.org/

Handcock, M. S., and Morris, M. (1999). Relative Distribution Methods in the Social Sciences. New York: SpringerVerlag.

Happé, F., and Ronald, A. (2008). The "fractionable autism triad": A review of evidence from behavioural, genetic, cognitive and neural research. Neuropsychol. Rev. 18, 287-304.

Happé, F., and Vital, P. (2009). What aspects of autism predispose to talent? Philos. Trans. R. Soc. B 364, 1369-1375.

Harpending, H., and Cochran, G. (2002). In our genes. Proc. Natl. Acad. Sci. U.S.A. 99, 10-12.

Harris, G. T., Rice, M. E., Hilton, N. Z. Lalumiére, M. L., and Quinsey, V. L. (2007). Coercive and precocious sexuality as a fundamental aspect of psychopathy. J. Pers. Disord. 21, 1-27. Haselton, M. G., and Gangestad, S. W. (2006). Conditional expression of women's desires and men's mate guarding across the ovulatory cycle. Horm. Behav. 49, 509-518.

Haselton, M. G., and Miller, G. F. (2006) Women's fertility across the cycle increases the short-term attractiveness of creative intelligence. Hum. Nat. 17, 50-73.

Hawks, J., Wang, E. T., Cochran, G. M., Harpending, H. C., and Moyzis, R. K. (2007). Recent acceleration of human adaptive evolution. Proc. Natl. Acad. Sci. U.S.A. 104, 20753-20758.

Hebebrand, J., Henninghausen, K., Nau, S., Himmelmann, G. W., Schulz, E. Schäfer, H., and Remschmidt, $\mathrm{H}$ (1997). Low body weight in male children and adolescents with schizoid personality disorders or Asperger's Disorders. Acta Psychiatr. Scand. 96 64-67.

Helt, M., Kelley, E., Kinsbourne, M., Pandey, J., Boorstein, H., Herbert, M., and Fein, D. (2008). Can children with autism recover? If so, how? Neuropsychol. Rev. 18, 339-366.

Henry, J. D., Bailey, P. E., and Rendell, P. G. (2008). Empathy, social functioning and schizotypy. Psychiatry Res 160 15-22.

Hill, K. (1993). Life history theory and evolutionary anthropology. Evol. Anthropol. 2, 78-88.

Hill, K., and Kaplan, H. (1999). Life history traits in humans: theory and empirical studies. Annu. Rev. Anthropol. 28 397-430.

Hoekstra, R. A., Bartels, M., Cath, D C., and Boomsma, D. I. (2008) Factor structure, reliability and criterion validity of the Autismspectrum Quotient (AQ): a study in Dutch population and patient groups. J. Autism Dev. Disord. 38 , 1555-1566

Hoekstra, R. A., Bartels, M., Verweij, C. J., and Boomsma, D. I. (2007) Heritability of autistic traits in the general population. Arch. Pediatr. Adolesc. Med. 161,372-377.

Horrobin, D. F. (1998). Schizophrenia: the illness that made us human. Med. Hypotheses 50, 269-288.

Hurst, R. M., Nelson-Gray, R. O., Mitchell, J. T., and Kwapil, T. R. (2007a). The relationship of Asperger's characteristics and schizotypal personality traits in a non-clinical adult sample. J. Autism Dev. Disord. 37, 1711-1720.

Hurst, R. M., Mitchell, J. T., Kimbrel, N. A., Kwapil, T. K., and Nelson-Gray, R. O. (2007b). Examination of the reliability and factor structure of the Autism spectrum Quotient (AQ) in a non-clinical sample. Pers. Individ. Dif. 43, 1938-1949.

Isles, A. R., Davies, W., and Wilkinson, L. S. (2006). Genomic imprinting and the social brain. Philos. Trans. R. Soc. B361, 2229-2237.

Jackson, J. J., and Kirkpatrick, L. A. (2007). The structure and measurement of human mating strategies: towards a multidimensional model of sociosexuality. Evol. Hum. Behav. $28,382-391$.

Jahshan, C. S., and Sergi, M. J. (2007). Theory of mind, neurocognition, and functional status in schizotypy. Schizophr. Res. 89, 278-286.

Jobe, L. E., and White, S. W. (2007). Loneliness, social relationships, and a broader autism phenotype in college students. Pers. Individ. Dif. 42, 1479-1489.

Jolliffe, T., and Baron-Cohen, S. (1997). Are people with autism or Asperger's syndrome faster than normal on the Embedded Figures Task? J. Child Psychol. Psychiatry 38, 527-534.

Kahn, R. S., and Davis, K. L. (1995). “New developments in dopamine and schizophrenia," in Psychopharmacology: The Fourth Generation of Progress, eds F.E. Bloom and D. J.Kupfer (New York, NY: Raven Press), 1193-1203.

Kaplan, H., Hill, K., Lancaster, J., and Hurtado, A. M. (2000). A theory of human life history evolution: diet, intelligence, and longevity. Evol. Anthropol. 9, 156-185.

Kaplan, H., and Robson, A. J. (2002). The emergence of humans: the coevolution of intelligence and longevity with intergenerational transfers. Proc. Natl. Acad. Sci. U.S.A. 99, 10221-10226.

Kaplan, H. S., and Gangestad, S. W. (2005). "Life history theory and evolutionary psychology," in The Handbook of Evolutionary Psychology, ed.D.M.Buss (Hoboken, NJ: John Wiley \& Sons), 68-95.

Kaufman, S. B., Kozbelt, A., Bromley, M. L., and Miller, G. F., (2007). "The role of creativity and humor in mate selection," in Mating Intelligence: Sex, Relationships, and the Mind's Reproductive System, eds G. Geher and G. Miller (Mahwah, NJ: Erlbaum), 227-262.

Keller, M. C. (2008). Problems with the imprinting hypothesis of schizophrenia and autism. Behav. Brain Sci. 31, 273-274. 
Keller, M. C., and Miller, C. K. (2006). Resolving the paradox of common harmful, heritable mental disorders: which evolutionary genetic models work best? Behav. Brain Sci. 29, 385-452.

Kenrick, D. T., and Keefe, R. C. (1992). Age preferences in mate reflect sex differences in reproductive strategies. Behav. Brain Sci. 15, 75-133.

Kimura, D. (1999). Sex and Cognition. Cambridge, MA: MIT Press.

Kimura, D. (2004). Human sex differences in cognition: fact, not predicament. Sex. Evol. Gend. 6, 45-53.

Kirkpatrick, L.A. (1998). “Evolution, pair bonding, and reproductive strategies: a reconceptualization of adult attachment," in Attachment Theory and Close Relationships, eds J.A. Simpson and W. S. Rholes (New York, NY: Guilford), 353-393.

Knickmeyer, R., Baron-Cohen, S., Raggatt, P., and Taylor, K. (2005). Foetal testosterone, social cognition, and restricted interests in children. J. Child Psychol. Psychiatry 45, 1-13.

Knickmeyer, R., Wheelwright, S., and Baron-Cohen, S. (2008). Sex-typical play: masculinization/defeminization in girls with an autism spectrum condition. J. Autism Dev. Disord. 38, 1028-1035.

Kokko, H., and Jennions, M. (2008). Parental investment, sexual selection and sex ratios. J. Evol. Biol. 21, 919-948.

Kölliker, M., Brodie, E. D. III, and Moore, A. (2005). The coadaptation of parental supply and offspring demand. Am. Nat. 166, 506-516.

Kölliker, M., and Richner, H. (2001). Parent-offspring conflict and the genetics of offspring solicitation and parental response. Anim. Behav. 62, 395-407.

Kramer, K. L. (2005). Children's help and the pace of reproduction: cooperative breeding in humans. Evol. Anthropol. 14, 224-237.

Kruger, D. J. (2008). Male financial consumption is associated with higher mating intentions and mating success. Evol. Psychol. 6, 603-612.

Langdon, R., and Coltheart, M. (1999). Mentalizing, schizotypy, and schizophrenia. Cognition 71, 43-71.

Langdon, R., and Coltheart, M. (2004). Recognition of metaphor and irony in young adults: the impact of schizotypal personality traits. Psychiatry Res. 125, 9-20.

Lutchmaya, S., Baron-Cohen, S., and Raggatt, P. (2002). Foetal testosterone and eye contact in 12 month old infants. Infant Behav. Dev. 25, 327-335.

Marco, E. J., and Skuse, D. H. (2006). Autism: lessons from the
X chromosome. Soc. Cogn. Affect. Neurosci. 1, 183-193.

Marlowe, F. (2000). Paternal investment and the human mating system. Behav. Processes 51, 45-61.

Marlowe, F. (2003). The mating system of foragers in the standard crosscultural sample. Cross Cult. Res. 37, 282-306.

Mata, I., Mataix-Cols, D., and Peralta, V. (2005). Schizotypal Personality Questionnaire-Brief: factor structure and influence of sex and age in a nonclinical population. Pers. Individ. Dif. 38, 1183-1192.

Mealey, L. (1995). The sociobiology of psychopathy: an integrated evolutionary model. Behav. Brain Sci. 18, 523-559.

Miller, G. F. (2000a). Mental traits as fitness indicator. Expanding evolutionary psychology's adaptationism. Ann. N. Y. Acad. Sci. 709, 62-74.

Miller, G. F. (2000b). The Mating Mind. How Sexual Choice Shaped the Evolution of Human Nature. London: Heinemann.

Miller, G. F., and Tal, I. R. (2007). Schizotypy versus openness and intelligence as predictors of creativity. Schizophr. Res. 93, 317-324.

Nettle, D. (2001). Strong Imagination: Madness, Creativity and Human Nature. Oxford: Oxford University Press.

Nettle, D. (2005). An evolutionary perspective on the extraversion continuum. Evol. Hum. Behav. 26, 363-373.

Nettle, D. (2006). Schizotypy and mental health amongst poets, artists and mathematicians. J. Res. Pers. 40, 876-890.

Nettle, D. (2008). Why is creativity attractive in a potential mate? Behav. Brain Sci. 31, 275-276.

Nettle, D., and Clegg, H. (2006). Schizotypy, creativity and mating success in humans. Proc. R. Soc. Lond. B 273, 611-615.

Pickup, G. (2006). Theory of mind and its relation to schizotypy. $\operatorname{Cog} n$. Neuropsychiatry 11, 117-192.

Pillsworth, E. G., Haselton, M. G., and Buss, D. M. (2004). Ovulatory shifts in female sexual desire. J. Sex Res. 41, 55-65.

Pollmann, M. M. H., Finkenauer, C., and Begeer, S. (2009). Mediators of the link between autistic traits and relationship satisfaction in a nonclinical sample. J. Autism Dev. Disord. 40, 470-478.

Quinlan, R.J. (2008). Human pair-bonds: evolutionary functions, ecological variation, and adaptive development. Evol. Anthropol. 17, 227-238.

R Development Core Team. (2008). R: A Language and Environment for Statistical Computing. Vienna: R
Foundation for Statistical Computing Available at http://www.R-project. org

Raine, A. (1991). The SPQ: a scale for the assessment of schizotypal personality based on DSM-III-R criteria. Schizophr. Bull. 17, 555-564.

Raine,A. (1992). Sex differences in schizotypal personality in a nonclinical population. J. Abnorm. Psychol. 101, 361-364.

Raine, A., Reynolds, C., Lencz, T., Scerbo, A., Tryphon, N., and Kim, D. (1994) Cognitive-perceptual, interpersonal and disorganized features of schizotypal personality. Schizophr. Bull. 20 191-201.

Räsänen, S., Pakaslahty, A., Syvälahti, R. Jones, P. B., and Isohanni, M. (2000). Sex differences in schizophrenia: a review. Nord. J. Psychiatry. 54, 37-45.

Rawlings, D. (2008). Relating humor preference to schizotypy and autism scores in a student sample. Humor 21 , 197-220.

Rawlings, D., and Locarnini, A. (2008). Dimensional schizotypy, autism, and unusual word associations in artists and scientists. J. Res. Pers. 42 , 465-471.

Revelle, W. (2008). The Psych Package Version 1.0-57. Available at http:// cran.r-project.org/

Ross, S. R., Lutz, C. J., and Bailey, S. E. (2002). Positive and negative symptoms of schizotypy and the five-factor model: a domain and facet level analysis. J. Pers. Assess. 79, 53-72.

Seltzer, M. M., Shattuck, P., Abbeduto, L. and Greenberg, J. S. (2004). Trajectory of development in adolescents and adults with autism. Ment. Retard. Dev. Disabil. Res. Rev. 10, 234-247.

Shaner, A., Miller, G. F., and Mintz J. (2004). Schizotypy as one extreme of a sexually selected fitness indicator. Schizophr. Res. 70, 101-109.

Shaner, A., Miller, G. F., and Mintz, J. (2008a). "Mental disorders as catastrophic failure of mating intelligence," in Mating Intelligence: Sex, Relationships, and the Mind's Reproductive System, eds G. Geher and G. F. Miller (Mahwah, NJ: Erlbaum), 193-224.

Shaner, A., Miller, G. F., and Mintz, J. (2008b). Autism as the low-fitness extreme of a parentally selected fitness indicator. Hum. Nat. 19, 389-413.

Shean, G., Bell, E., and Cameron, C. D. (2007). Recognition of nonverbal affect and schizotypy. J. Psychol. 141, 281-291.

Silverman, I., and Eals, M. (1992). "Sex differences in spatial abilities: evolutionary theory and data," in The Adapted Mind, eds J. H. Barkow, L. Cosmides, and J. Tooby (New
York, NY: Oxford University Press), 533-549.

Simpson, J. A., and Belsky, J. (2008). "Attachment theory within a modern evolutionary framework," in Handbook of Attachment: Theory, Research, and Clinical Applications, 2nd Edn, eds P. R. Shaver and J. Cassidy (New York, NY: Guilford), 131-157.

Skuse, D. H. (2005). X-linked genes and mental functioning. Hum. Mol. Genet. 14, 27-32.

Smiseth, P. T., Wright, J., and Kölliker, M. (2008). Parent-offspring conflict and coadaptation: behavioural ecology meets quantitative genetics. Proc. $R$. Soc. Lond. B 275, 1823-1830.

Sobanski, E., Marcus, A., Henighausen, K., Hebebrand, J., and Schmidt, M. H. (1999). Further evidence for a low body weight in male children and adolescents with Asperger's disorder. Eur. Child Adolesc. Psychiatry 8, 312-314.

Spikins, P. (2009). Autism, the integrations of 'difference' and the origins of modern human behaviour. Camb. Archaeol. J. 19, 179-201.

Stone, E. A., Shackelford, T. K., and Buss, D. M. (2007). Sex ratio and mate preferences. Eur. J. Soc. Psychol. 37, 288-296.

Tempelhof, T. C., and Sabura Allen, J. (2008). Partner-specific investment strategies: Similarities and differences in couples and associations with sociosexual orientation and attachment dimensions. Pers. Indiv. Diff. 45, 41-48.

Trivers, R. L. (1972). "Parental investment and sexual selection," in Sexual Selection and the Descent of Man, ed. B. Campbell (Chicago, IL: Aldine), 136-179.

Úbeda, F. (2008). Evolution of genomic imprinting with biparental care: implications for Prader-Willi and Angelman syndromes. PLoS Biol. 6, e208. doi: 10.1371/journal.pbio.0060208.

Venables, P. H., and Bailes, K. (1994). The structure of schizotypy, in relation to subdiagnoses of schizophrenia to sex and age. Br. J. Clin. Psychol. 33, 277-294.

Voight, B. F., Kudaravalli, S., Wen, X., and Pritchard, J. K. (2006). A map of recent positive selection in the human genome.PLoS Biol. 4, e72. doi: 10.1371/journal.pbio.0040072.

Voracek, M., and Dressler, S. G. (2006). Lack of correlation between digit ratio (2D:4D) and Baron-Cohen's "Reading the Mind in the Eyes" test, empathy, systemizing, and autism-spectrum quotients in a general population sample. Pers. Individ. Dif. 41, 1481-1491.

Wakabayashi, A., Baron-Cohen, S., and Wheelwright, S. (2006). Are autistic traits an independent personality dimension? A study of the 
Autism-spectrum Quotient (AQ) and the NEO PI-R. Pers. Individ. Dif. 41, 873-883.

Weinstein, S., and Graves, R.E. (2002). Are creativity and schizotypy products of a right hemisphere bias? Brain Cogn 49, 138-151.

Wheelwright, S., Baron-Cohen, S., Goldenfeld, N., Delaney, J., Fine, D., Smith, R., Weil, L., and Wakabayashi, A. (2006). Predicting Autism spectrum Quotient (AQ) from the Systemizing
Quotient-Revised (SQ-R) and Empathy Quotient (EQ). Brain Res. 1079, 47-56.

Wilkins, J. F., and Haig, D. (2003). What good is genomic imprinting: the function of parent-specific gene expression. Nat. Rev. Genet. 4, 1-10.

Williams, L. M., and Barry, J. (2003). Do sex differences in emotionality mediate sex differences in traits of psychosis-proneness? Cogn. Emot. 17, 747-758.
Winking, J., Kaplan, H., Gurven, M., and Rucas, S. (2007). Why do men marry and why do they stray? Proc. R. Soc. B 274, 1643-1649.

Received: 16 April 2010; paper pending published: 30 April 2010; accepted: 14 July 2010; published online: 30 August 2010. Citation: Del Giudice M, Angeleri R, Brizio A and Elena MR (2010) The evolution of autistic-like and schizotypal traits: a sexual selection hypothesis. Front. Psychology 1:41. doi: 10.3389/fpsyg.2010.00041
This article was submitted to Frontier in Evolutionary Psychology, a specialty of Frontiers in Psychology. Copyright (C) 2010 Del Giudice, Angeleri, Brizio and Elena. This is an open-access article subject to an exclusive license agreement between the authors and the Frontiers Research Foundation, which permits unrestricted use, distribution, and reproduction in any medium, provided the original authors and source are credited. 